\title{
SCC Aerosol Transport Model Summary Report
}

Spent Fuel and Waste Disposition

\author{
Prepared for \\ US Department of Energy \\ Spent Fuel and Waste Science and \\ Technology \\ Stylianos Chatzidakis \\ Oak Ridge National Laboratory
}

December 20, 2018

M3SF-18OR010201072

ORNL/SPR-2018/1072

APPROVED FOR PUBLIC RELEASE.

DISTRIBUTION IS UNLIMITED. 
This report was prepared as an account of work sponsored by an agency of the United States Government. Neither the United States Government nor any agency thereof, nor any of their employees, makes any warranty, express or implied, or assumes any legal liability or responsibility for the accuracy, completeness, or usefulness of any information, apparatus, product, or process disclosed, or represents that its use would not infringe privately owned rights. Reference herein to any specific commercial product, process, or service by trade name, trademark, manufacturer, or otherwise, does not necessarily constitute or imply its endorsement, recommendation, or favoring by the United States Government or any agency thereof. The views and opinions of authors expressed herein do not necessarily state or reflect those of the United States Government or any agency thereof. 


\section{ACKNOWLEDGMENTS}

This research was sponsored by the Spent Fuel and Waste Science and Technology Program of the US Department of Energy and was carried out at Oak Ridge National Laboratory under contract DE-AC0500OR22725 with UT-Battelle, LLC.

This report was developed with significant contributions, expert input, and guidance from Sam Durbin and Eric Lindgren at Sandia National Laboratories.

The author would like to thank Program Managers Sylvia Saltzstein at Sandia National Laboratories and John Scaglione at Oak Ridge National Laboratory for providing guidance and support to this project, and Andrea Beatty at Oak Ridge National Laboratory for administrative support. 


\section{SUMMARY}

This report documents work performed under the Spent Fuel and Waste Disposition Campaign for the US Department of Energy Office of Nuclear Energy. This work was performed to fulfill the Level 3 milestone M3SF-18OR010201072 "Summary Report on Aerosol Transport Through Cracks Modeling" within work package SF-18OR01020108 "Stress Corrosion Cracking - ORNL."

Under certain conditions, dry storage confinement leak-tightness could be threatened and could yield a release of nuclear aerosols to the environment through penetrating canister cracks [NWTRB 2010, ANL 2014, NEI 2016, EPRI 2017a, NRC 2012, NRC 2018]. Previous work identified and evaluated mitigation methods and techniques for addressing potential future deficiencies associated with retrievable welded stainless steel canisters and their components that are part of the confinement boundary [DOE 2017a, DOE 2017b, DOE 2017c]. Considerable progress has been made in quantifying the source term; however, little attention has been given to the leakage itself and the source term reducing processes inside the leak path. Limited experimental evidence is available on the importance of aerosol retention in CISCC cracks through stainless steel canisters. Nevertheless, the accuracy of consequence assessments can be greatly improved by taking the leak path deposition of aerosol into account in the source term. We consider the filtration effect of such CISCC cracks interestingly relevant to the source term assessments. An important side effect of aerosol deposition in leak paths could be the plugging of the leak path. Further research into this phenomenon is desirable.

The purpose of the present work is to introduce a generic and reliable numerical model for prediction of aerosol transport, deposition, and plugging in leak paths similar to stress corrosion cracks while accounting for potential plugging formation. The model is dynamic (changing leak path geometry due to plugging) and it relies on the numerical solution of the aerosol transport equation in one dimension using finite differences. An extensive validation exercise (particle diameters: 0.01-10 $\mu \mathrm{m}$ and pressure difference up to $12 \mathrm{kPa}$ ) was conducted based on comparisons with experimental and theoretical data. The developed model is fairly general since it is based on a generic mechanistic description of the aerosol flow and particle deposition in the leak path, without requiring experimental fittings other than using the leak rate parameters commonly available in practical applications. Despite the approximate agreement of the model with the experimental data, the obtained predictions can be qualified as realistic. This is a major achievement of the model, which has been based on generic aerosol mechanics with no reference or adjustment to experimental data.

Particle penetration through CISCC cracks with height up to $100 \mu \mathrm{m}$ was then estimated using the validated numerical model and by considering the effects of three major deposition mechanisms: diffusion, gravitational settling, and inertial impaction. Particles were assumed to be spherical with a density of $8 \mathrm{~g} / \mathrm{cm}^{3}$ (to represent particles that may be released within a canister, e.g., Co-60 from CRUD or $\mathrm{UO}_{2}$ particles from fuel pellets) and with diameters ranging from 0.01 to $10 \mu \mathrm{m}$. Main conclusions of this study, summarized partially in Figure S-1, are:

- Diffusion governs the deposition of particles with $\mathrm{d}_{\mathrm{p}}<0.1 \mu \mathrm{m}$. Inertial deposition in the high flow rate regime and gravitational settling in the low flow rate regime govern the deposition for particles having diameter $d_{p}>1 \mu \mathrm{m}$.

- Particles of several microns in diameter can hardly penetrate through cracks because of the highly efficient removal of such particles by interaction deposition or gravitational settling.

- For CISCC cracks with height $<100 \mu \mathrm{m}$, particles having diameters in the range 0.1-0.5 $\mu \mathrm{m}$ have the highest penetration across the whole particle spectrum. Larger and smaller particles are readily removed in cracks under the gravitation settling and diffusion, respectively.

- Penetration factor becomes negligible for particles with diameters larger than $1 \mu \mathrm{m}$ even when crack opening is $100 \mu \mathrm{m}$. For crack heights less than $30 \mu \mathrm{m}$, penetration is practically zero. This 
indicates that penetration varies strongly with crack height and is significantly reduced with smaller crack heights.

- Significant pressure difference is needed, larger than $50 \mathrm{~Pa}$, for considerable penetration to occur from a $30 \mu \mathrm{m}$ crack. Even when $\Delta \mathrm{P}=200 \mathrm{~Pa}$, penetration is less than $60 \%$. For $\Delta \mathrm{P}=50 \mathrm{~Pa}$, penetration is less than $20 \%$ and practically zero for smaller pressure difference.

- Practically no aerosol release is predicted for cracks with opening displacement ("height") less than $50 \mu \mathrm{m}$ when ambient conditions prevail. Further, no particles with diameter $>1 \mu \mathrm{m}$ will be released for cracks with opening displacement ("height") less than $100 \mu \mathrm{m}$.

We believe that the modeling calculations presented in this report can provide important insight into the expected values of aerosol release through CISCC cracks and the factors that affect them. Further progress will require (i) improvements to refine the model and include depressurization regime (transient state) and (ii) additional experimental studies for model validation. Advances in this area hold the promise of improving the accuracy of consequence assessments and reducing the uncertainty of radiological consequence predictive analyses by taking the leak path deposition of aerosol into account in the source term.

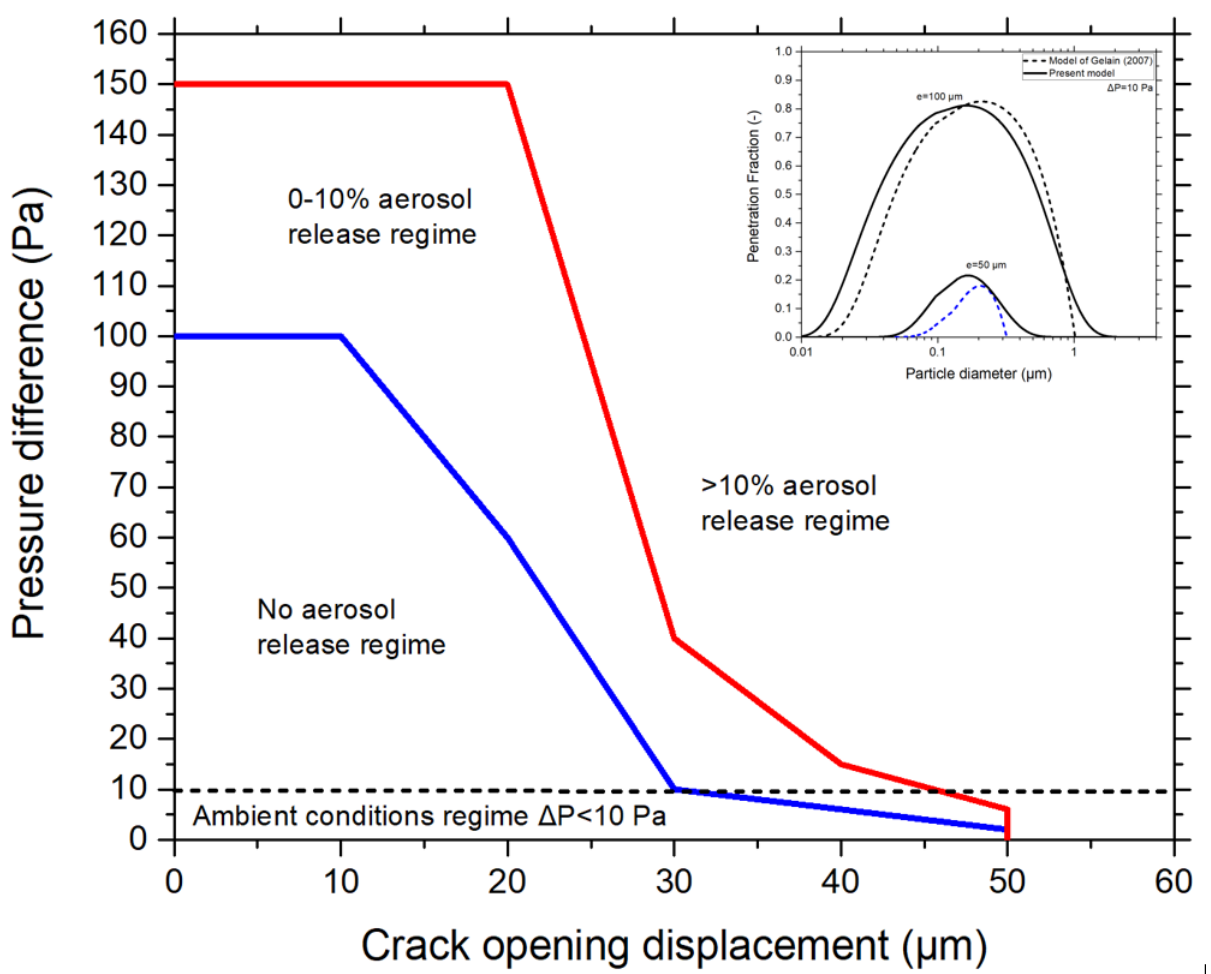

Figure S-1. Regimes for aerosol transport through CISCC cracks as a function of pressure difference (penetration as a function of particle size spectrum is shown in upper right figure). "Ambient conditions" refers to conditions following canister depressurization. Highest penetration efficiency is observed for particles in the range 0.1-0.5 $\mu \mathrm{m}$. No particles with diameter $>1 \mu \mathrm{m}$ will be released for cracks with opening displacement ("height") less than $100 \mu \mathrm{m}$. Notes: (i) predictions assume steady state and small

pressure differences expected following canister depressurization; (ii) uniform crack geometry with smooth inner surface and steady airflow through the crack was assumed; however, in real cracks, irregular geometry and surface roughness might increase particle deposition significantly. 
This page is intentionally left blank. 


\section{CONTENTS}

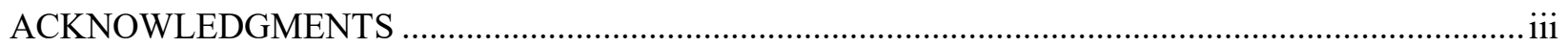

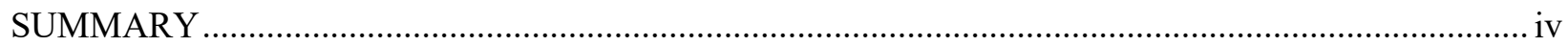

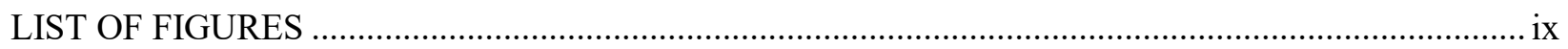

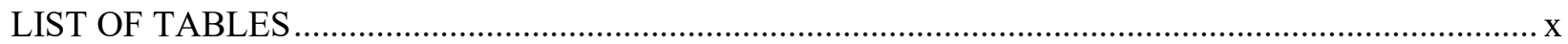

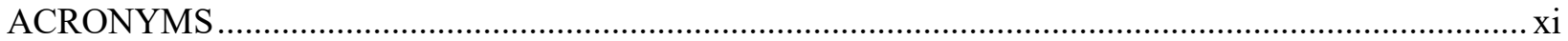

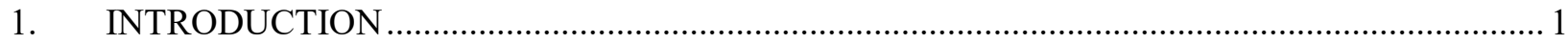

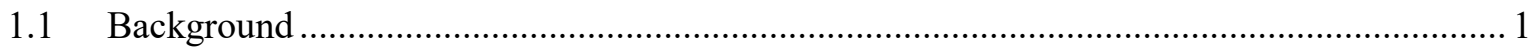

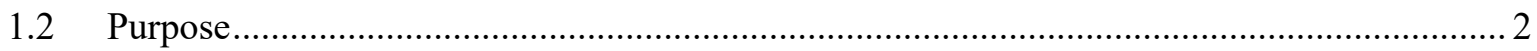

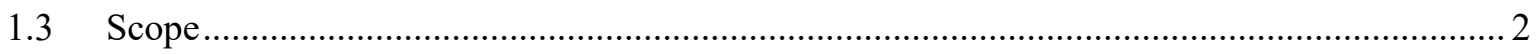

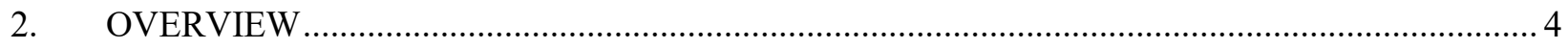

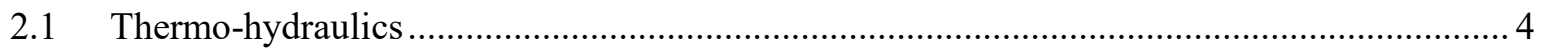

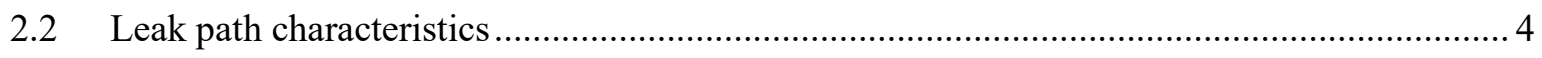

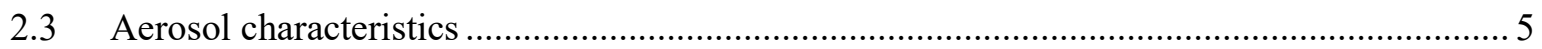

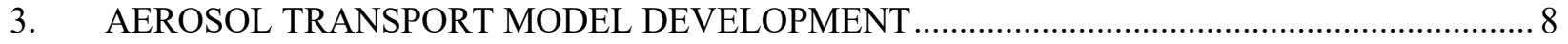

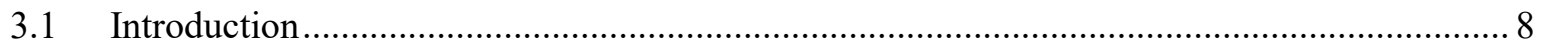

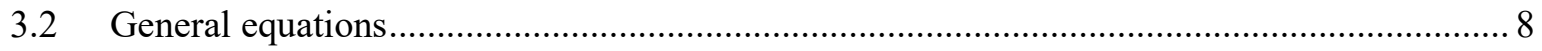

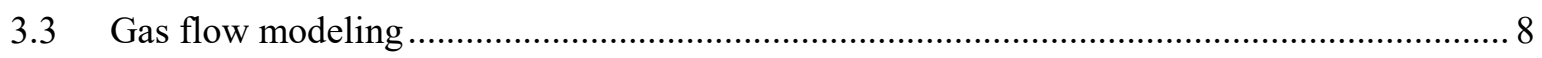

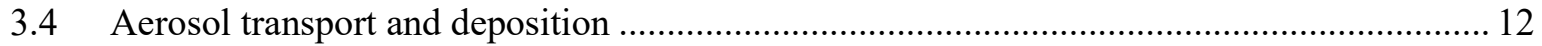

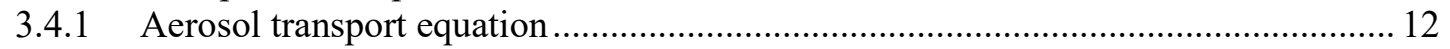

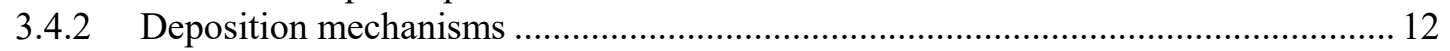

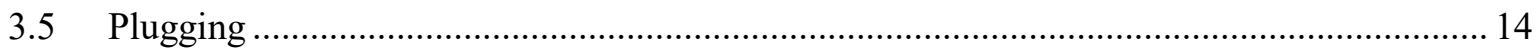

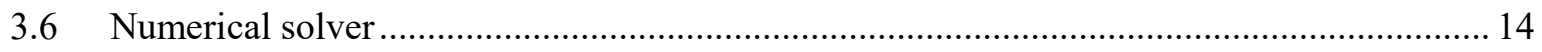

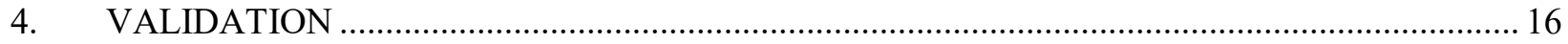

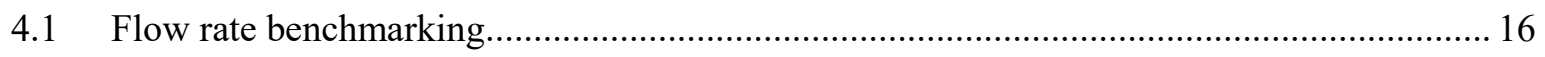

4.2 Comparison with empirical model by Gelain and Vendel (2007)....................................... 18

4.3 Comparison with experiments by Liu and Nazaroff (2003) ............................................. 22

4.4 Comparison with experiments by Gelain \& Vendel (2007) ............................................... 23

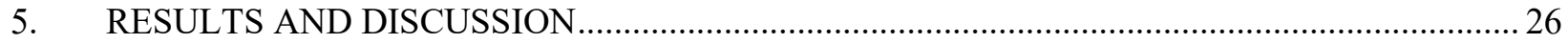

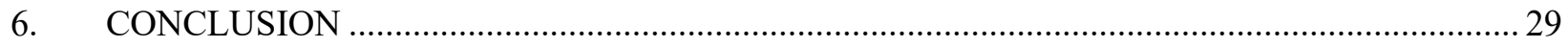

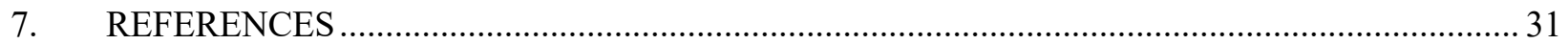


This page is intentionally left blank. 


\section{LIST OF FIGURES}

Figure S-1. Regimes for aerosol transport through CISCC cracks as a function of pressure difference (penetration as a function of particle size spectrum is shown in upper right figure). "Ambient conditions" refers to conditions following canister depressurization. Highest penetration efficiency is observed for particles in the range $0.1-0.5 \mu \mathrm{m}$. No particles with diameter $>1 \mu \mathrm{m}$ will be released for cracks with opening displacement ("height") less than $100 \mu \mathrm{m}$. Notes: (i) predictions assume steady state and small pressure differences expected following canister depressurization; (ii) uniform crack geometry with smooth inner surface and steady airflow through the crack was assumed; however, in real cracks, irregular geometry and surface roughness might increase particle deposition significantly.....

Figure 1. Friction factor vs. Reynolds number for crack-like geometries; the transition from laminar to turbulent flow occurs at $\mathrm{Re}=5-10$.

Figure 2. Friction factor vs. Reynolds number for capillaries; the transition from laminar to turbulent flow occurs at $\mathrm{Re}=400$...

Figure 3. Block diagram for numerical solution of the aerosol transport equation. 15

Figure 4. Flow rate vs. pressure difference for rectangular geometry [Sutter et al.]. 16

Figure 5. Reynolds number vs. pressure difference for rectangular geometry [Sutter et al.]. 17

Figure 6. Flow rate vs. pressure difference for cylindrical geometry [Sutter et al.]. 17

Figure 7. Reynolds number vs. pressure difference for cylindrical geometry [Sutter et al.]. 18

Figure 8. Retained fraction of particles with $d_{p}=60 \mathrm{~nm}$ as a function of flow rate. 20

Figure 9. Retained fraction of particles with $\mathrm{d}_{\mathrm{p}}=0.8 \mu \mathrm{m}$ as a function of flow rate. 20

Figure 10. Retained fraction of particles with $d_{p}=1.1 \mu \mathrm{m}$ as a function of flow rate. 21

Figure 11. Retained fraction of particles with $d_{p}=4.1 \mu \mathrm{m}$ as a function of flow rate. 21

Figure 12. Penetration fraction of particles as a function of particle diameter. 22

Figure 13. Deposition fractions for particles of aerodynamic diameter of $60 \mathrm{~nm}$. 24

Figure 14. Deposition fractions for particles of aerodynamic diameter of $0.8 \mu \mathrm{m}$. 24

Figure 15. Deposition fractions for particles of aerodynamic diameter of $1.1 \mu \mathrm{m}$. .25

Figure 16. Deposition fractions for particles of aerodynamic diameter of $4.1 \mu \mathrm{m}$. . .25

Figure 17. Penetration fraction as a function of particle diameter for two crack heights, $\mathrm{e}=50 \mu \mathrm{m}$ and $\mathrm{e}=100 \mu \mathrm{m}$, and $\Delta \mathrm{P}=10 \mathrm{~Pa}$.

Figure 18. Penetration fraction as a function of particle diameter for crack height $\mathrm{e}=30 \mu \mathrm{m}$ and $\Delta \mathrm{P}=50 \mathrm{~Pa}, 100 \mathrm{~Pa}$, and $200 \mathrm{~Pa}$.

Figure 19. Regimes for aerosol transport through CISCC cracks as a function of pressure difference (penetration as a function of particle size spectrum is shown in upper right figure). "Ambient conditions" refers to conditions following canister depressurization. Highest penetration efficiency is observed for particles in the range $0.1-0.5 \mu \mathrm{m}$. No particles with diameter $>1 \mu \mathrm{m}$ will be released for cracks with opening displacement ("height") less than $100 \mu \mathrm{m}$. 


\section{LIST OF TABLES}

Table 1. Summary of aerosol penetration tests in open literature. 


\section{ACRONYMS}

$\begin{array}{ll}\text { CISCC } & \text { chloride-induced stress corrosion cracking } \\ \text { CFR } & \text { US Code of Federal Regulations } \\ \text { DOE } & \text { US Department of Energy } \\ \text { DPC } & \text { dual-purpose canister } \\ \text { DSS } & \text { dry storage system } \\ \text { EPRI } & \text { Electric Power Research Institute } \\ \text { GDE } & \text { general dynamic equation } \\ \text { NWTRB } & \text { US Nuclear Waste Technical Review Board } \\ \text { ORNL } & \text { Oak Ridge National Laboratory } \\ \text { SCC } & \text { stress corrosion cracking }\end{array}$


This page is intentionally left blank. 


\section{SPENT FUEL AND WASTE DISPOSITION PROGRAM SCC AEROSOL TRANSPORT MODEL SUMMARY REPORT}

\section{INTRODUCTION}

Under certain conditions, dry storage confinement leak-tightness could be threatened and could yield a release of nuclear aerosols to the environment through penetrating canister cracks [NWTRB 2010, ANL 2014, NEI 2016, EPRI 2017a, NRC 2012, NRC 2018]. The potential consequences associated with unmitigated chloride-induced stress corrosion cracking (CISCC) of welded stainless steel canisters have not been specifically analyzed. The hypothetical CISCC degradation scenario could include through-wall cracking followed by loss of inert backfill overpressure, air ingress, and reduced heat removal capacity. Additional degradation or complicating factors could follow if the canister remains in storage and cracking is unmitigated.

Because few data are presently available to quantify or even preclude the possibility of aerosol leakage, a specific action is launched in the framework of consequence analysis of dry storage systems. In this context, theoretical and experimental investigations will be developed to validate a phenomenological model to predict, in a realistic way, the retention of aerosols in a leak pathway that may be found in welded stainless steel canisters. This model can be readily applied by regulators, industry, and shareholders to reduce the uncertainty in radiological consequence predictive analyses. This report outlines the development of a generic numerical model of aerosol transport, deposition, and plugging through capillaries, slots, and cracks.

\subsection{Background}

Approximately $90 \%$ of the dry storage systems (DSSs) currently in use consist of welded stainless steel canisters placed in concrete or metal overpacks; the remaining $10 \%$ of the DSSs in use are bolted lid metal casks [DOE 2015]. Although the sizes and configurations of DSSs can vary significantly, leaktightness is ensured by a continuous pressure boundary consisting of metallic gaskets (e.g., bolted lid metal casks), or metallic components that are welded together (e.g., welded canisters). The confinement boundary integrity must be maintained over the duration of the storage license, including the initial licensing period ( 40 years maximum) and any subsequent license renewal periods (increments of up to 40 additional years) [NRC 2016]. A breach in the confinement system could cause a safety concern and result in noncompliance with several regulations, e.g., 10 US Code of Federal Regulations (CFR) 72.122(h)(1), among others [10 CFR 72].

If particulates are present in the backfill gas, then the main concern associated with a through-wall crack formation is the release of radioactivity to the environment. If particulates are not present, then the main concern is the depressurization time of the cask over which an inert atmosphere can be maintained within the container. Once the container has been depressurized, then oxygen can begin to diffuse through the breach into the container. As the decay heat from the spent fuel decreases with time, the temperature and thus the pressure within the container will decrease, as well. This could lead to convective flow of oxygen into the container, resulting in oxidation of fuel rod cladding and any exposed fuel. This oxidation could, under certain conditions, transform radionuclides into more mobile forms.

Previous work has identified existing dose consequence evaluations which rely on uncertain assumptions and significant conservatism at every step, including quantifying the source term, determining release fractions, and defining the exposure conditions [EPRI 2017b]. However, particle penetration through the confinement boundary may be significantly lower, even by orders of magnitude, in comparison to that 
associated with the air leakage rate. Indeed, earlier work on particle transport through concrete cracks and nuclear containments has shown that under certain conditions, the penetration fraction can be significantly reduced. Particularly, Mosley et al. [Mosley 2001] designed a chamber to measure particle penetration through horizontal slits between aluminum plates for a range of particle diameters $(0.05-5 \mu \mathrm{m})$ and found that particle penetration is a strong function of particle size. Experiments [Liu and Nazaroff 2001] for idealized rectangular cracks showed that particles of $0.1-10 \mu \mathrm{m}$ have the highest penetration efficiency. For horizontal fine capillaries [Clement 1995] the significance of the three main deposition mechanisms (Brownian, gravitational, impaction) was determined by capillary radius, length, and fluid velocity. More recent experiments [Sandia 2018] showed that approximately $44 \%$ of particulate mass remains within the canister volume.

\subsection{Purpose}

The purpose of the present work is to explore particle penetration through leakage paths in CISCC cracks and to introduce and validate a numerical model of aerosol transport, deposition, and plugging through capillaries, slots, and cracks. It includes: (i) development of numerical model to analyze the various deposition processes in leak paths and provide quantitative estimates of penetration factors as well as an understanding of the variables that affect them, (ii) verification of model validity with theoretical and experimental data, (iii) parametric analysis for different CISCC scenarios including various particle sizes, pressures, and crack dimensions.

\subsection{Scope}

This report applies only to all licensed DSSs with welded stainless steel canisters and the components that are part of the confinement boundary but no longer conform to the regulatory requirements for continued storage or transportation offsite. The scope of this report does not include any aerosol leakage during depressurization, i.e., transient state, instead it focuses on any effects following depressurization and when pressure differences are small, e.g., $\Delta \mathrm{P}<10 \mathrm{~Pa}$. However, the authors recognize that significant aerosol leakage may occur during depressurization; with that in mind the model will be developed and validated to facilitate transient state calculations. 
This page is intentionally left blank. 


\section{OVERVIEW}

An aerosol is a dispersion of small solid particles suspended in a gas. The term aerosol refers to both the particle and the suspending gas. Particles typically represent a very small fraction of the total aerosol mass. The two phases are one-way coupled, i.e., the gas phase influences the behavior of the particulate phase while the particle phase has no influence on the hydrodynamics of the gas phase. As the aerosol transport, deposition, and retention involve the thermohydraulic behavior of the canister and of the crack, as well as the geometric characteristics of the leak path and the aerosol features, the minimum set of parameters can be identified within these groups:

- Thermo-hydraulics: the most important parameters within this group are pressure inside the canister, gas composition, pressure drop, and wall temperature along the crack.

- Leak path characteristics: the parameters to be considered are mainly the crack path and its hydraulic diameter; information on the crack's section, shape, and curvature are also very important.

- Aerosol characteristics: aerosol average composition, concentration and size distribution are the reference parameters, while other parameters regarding aerosol morphology can be only taken with large uncertainties.

The main thermo-hydraulics, leak path and aerosol characteristics are summarized in the following sections.

\subsection{Thermo-hydraulics}

Generally, gas flow is dependent on pressure, temperature, crack morphology, gas properties, and friction factor. This is described mathematically as follows:

$$
q=f(T, \Delta P, e, l, L, r, \lambda, R e),
$$

where $q$ is the mass flow rate $\left(\mathrm{kg} \mathrm{s}^{-1}\right), e$ is the crack width $(\mathrm{m}), l$ is the crack extent $(\mathrm{m}), \Delta P$ is the difference between upstream and downstream pressures $(\mathrm{Pa}), L$ is the crack length or leak path $(\mathrm{m}), r$ is the ideal gas mass constant $\left(\mathrm{J} \mathrm{kg}^{-1} \mathrm{~K}^{-1}\right), T$ is the temperature $(\mathrm{K}), \lambda$ is the friction loss coefficient $(-)$, and $R e$ is the Reynolds number (-).

\subsection{Leak path characteristics}

An extensive review of CISCC cracks and leak path characteristics can be found in [DOE 2018]. Main conclusions from this study are:

- Location: Most intergranular-SCC develops next to welds with straight or winding cracks that are oriented almost parallel to the weld.

- Quantity: Single cracking is most common, but occasionally, two cracks are formed on each side of the weld.

- Branching: In the through thickness direction, intergranular-SCC is typically winding or lightly bent, and macroscopic branching is rare.

- Roughness: The surface roughness is normally on a grain size magnitude, and the cracks are particularly narrow if secondary corrosion is minimal.

- Aperture: Experiments have shown that SCC exhibits crack opening displacements ("height") of 15-30 $\mu \mathrm{m}$ (median value).

- Opening area: Typical values for crack opening area vary from 0.004 to $0.025 \mathrm{~cm}^{2}$ based on a crack length of $2.5 \mathrm{~cm}$. 
- Leakage rate: Pressurization is calculated to dissipate within 1 day for all canister designs when assuming a crack opening area of $0.025 \mathrm{~cm}^{2}$. Cases with a crack opening area of $0.004 \mathrm{~cm}^{2}$ required up to 52 days to dissipate.

\subsection{Aerosol characteristics}

Aerosol leakage depends on aerosol size, properties, and deposition mechanisms. A number of deposition mechanisms in leaks must be considered, each with a deposition velocity. The aerosol leakage is described mathematically as

$$
F r=f\left(D, Q, v_{g}, v, \rho_{g}, d_{p}, \mu, e, l, L, P, S t k\right),
$$

where $\mathrm{Fr}$ is the deposited fraction due to deposition mechanisms, $D$ is the aerosol diffusion coefficient $\left(\mathrm{m}^{2} \mathrm{~s}^{-1}\right), Q$ is the volume flow rate $\left(\mathrm{m}^{3} \mathrm{~s}^{-1}\right), v_{g}$ is the aerosol gravitational settling velocity $\left(\mathrm{m} \mathrm{s}^{-1}\right), v$ is the mean fluid velocity $\left(\mathrm{m} \mathrm{s}^{-1}\right), \rho_{g}$ is the aerosol density $\left(\mathrm{kg} \mathrm{m}^{-3}\right), d_{p}$ is the aerosol diameter $(\mathrm{m}), \mu$ is the fluid dynamic viscosity (Pa s), $e$ is the crack width $(\mathrm{m}), l$ is the crack extent $(\mathrm{m}), L$ is the crack length or leak path $(\mathrm{m})$, and $\mathrm{P}$ is the absolute pressure $(\mathrm{Pa})$. Stk is the Stokes number $(-)$.

Aerosol characteristics are summarized below:

- Mass density: Aerosol mass densities observed in experiments reported in open literature for aerosols of powdered radioactive oxides and suitable surrogates range from $9.8 \mathrm{E}-9 \mathrm{~g} / \mathrm{cm}^{3}$ to $9.0 \mathrm{E}-6 \mathrm{~g} / \mathrm{cm}^{3}$.

- Size: Airborne radionuclides as particles (i.e., aerosol) that can be transported through air and inhaled into the human respiratory system are commonly assumed to include particles with aerodynamic diameters of $10 \mu \mathrm{m}$ or less.

- Deposition mechanisms: Deposition mechanisms transport aerosol to the walls of the leak path due to gas flow, gradients or external forces. Deposition mechanisms are summarized below:

- Diffusion: Very small particles $(\mathrm{d}<0.1 \mu \mathrm{m})$ may be transported to the walls of the leak path by diffusion. Generally, diffusive deposition is of minor importance for the source term because it is only efficient for very small particles that carry negligible mass.

- Electrophoresis: Aerosol particles can be deposited by electrophoresis in electrical fields arising due to charges at the particles or at the walls (or both). Due to the relatively high radiation fields, the particles will be a charge equilibrium and only minor charging of walls is to be expected.

- Thermophoresis: Thermophoretic deposition due to an aerosol warmer than the walls of the leak can occur. Rough calculations indicate that thermophoresis is relatively unimportant in in the removal of particles in leak paths.

- Diffusiophoresis: Diffusiophoretic deposition, is particle removal due to water vapor condensing onto leak path surfaces. The role of diffusiophoresis in removal during wall penetration will be insignificant.

- Gravitational: Gravitational settling removes particles of all upward facing walls and becomes increasingly important for larger particle diameters and for lower flow rate. As a result, particle larger than $\sim 1 \mu \mathrm{m}$ have a very small chance of penetration. Knowledge of flow rate and diameter of the leaking aerosol is of great importance for introduction in the source term of gravitation settling in leaks.

- Inertial impaction: Inertial deposition is likely to be the most important removal process of aerosols in leak paths. 
- Source term: Source term includes radionuclides comprising the fuel rods (fines, volatiles, and gas) and radionuclides on the surfaces of the fuel rods (crud).

- Past experiments: Several studies have been conducted to predict gas flow rate and aerosol transfer through crack paths, with an emphasis on aerosol leakage in nuclear containments. A few experimental studies have investigated particle penetration [Mosley et al. 2001, Gelain and Vendel 2007, Nelson and Johnson 1975] and penetration of reactive gases through leaks [Liu and Nazaroff 2003]. Other investigators have presented theoretical models for particle penetration [Liu and Nazaroff 2001] and plugging [Clement 1995, Williams 1994, Mitrakos et al. 2008]. Table 1 shows main parameters used in experiments aiming to simulate aerosol transport in cracks. Experiments relevant to this study are those of Mosley et al. (2001) Liu and Nazaroff (2003), Gelain and Vendel (2007), Lai et al. (2012) and Sandia (2018).

- It was found that particle penetration through narrow horizontal slits is a strong function of particle size and that particles of $0.1-10 \mu \mathrm{m}$ have the highest penetration efficiency.

- For particles larger than $10 \mu \mathrm{m}$, gravitational settling plays a significant role in particle deposition, while for particles ranging from 0.1 to $1.0 \mu \mathrm{m}$, Brownian diffusion governs particle deposition.

- It has been suggested that particles smaller than $10 \mu \mathrm{m}$ are not likely to adhere with other particles or re-entrained into the fluid. Therefore, when more particles deposit, the crack would be eventually blocked. 
Table 1. Summary of aerosol penetration tests in open literature.

\begin{tabular}{|c|c|c|c|c|c|c|}
\hline Experiment & Type & Material & $\Delta \mathbf{P}$ & dp & $\mathrm{D}(\operatorname{or} \mathbf{H} \times \mathbf{W}) *$ & $\mathbf{L}$ \\
\hline Morton \& Mitchell (1994) & Capillary & $\mathrm{n} / \mathrm{a}$ & $20-80 \mathrm{kPa}$ & $1-10 \mu \mathrm{m}$ & $28-35 \mu \mathrm{m}$ & $19-21 \mathrm{~mm}$ \\
\hline Lewis (1995) & Slot & $\mathrm{n} / \mathrm{a}$ & $10 \mathrm{kPa}$ & $1-6 \mu \mathrm{m}$ & $100 \mu \mathrm{m} \times 40 \mathrm{~mm}$ & $\mathrm{n} / \mathrm{a}$ \\
\hline Mosley et al. (2001) & Slot & Aluminum & $2-20 \mathrm{~Pa}$ & $0.05-5 \mu \mathrm{m}$ & $508 \mu \mathrm{m} \times 433 \mathrm{~mm}$ & $102 \mathrm{~mm}$ \\
\hline Liu \& Nazaroff (2003) & Slot & Concrete & $4-10 \mathrm{~Pa}$ & $0.02-7 \mu \mathrm{m}$ & $0.25 \mathrm{~mm}, 1 \mathrm{~mm}$ & $4.5 \mathrm{~cm}$ \\
\hline Gelain \& Vendel (2007) & Crack & Concrete & $0-12 \mathrm{kPa}$ & $0.8 ; 1.1 ; 4.1 \mu \mathrm{m}$ & $49.2 \mu \mathrm{m} \times 11.8 \mathrm{~m}$ & $0.1 \mathrm{~m}$ \\
\hline Tian et al. (2017) & Capillary & Silica & $60-450 \mathrm{kPa}$ & $<0.3 \mu \mathrm{m}$ & $5-20 \mu \mathrm{m}$ & $10-80 \mathrm{~mm}$ \\
\hline Lai et al. (2012) & Slot & Aluminum & $2-8 \mathrm{~Pa}$ & $20-500 \mathrm{~nm}$ & $50 \mathrm{~mm} \times 250 \mathrm{~mm}$ & $90 \mathrm{~mm}$ \\
\hline Nelson \& Johnson (1975) & Capillary & $\mathrm{n} / \mathrm{a}$ & $3 \mathrm{kPa}$ & $3-5 \mu \mathrm{m}$ & $520 \mu \mathrm{m}, 1,070 \mu \mathrm{m}$ & $4-8 \mathrm{~cm}$ \\
\hline Sandia (2018) & Slot & Steel & $700 \mathrm{kPa}$ & $1 \mu \mathrm{m}$ & $28.9 \mu \mathrm{m} \times 8.86 \mathrm{~mm}$ & $12.7 \mathrm{~mm}$ \\
\hline
\end{tabular}

*D: diameter (for capillary); $\mathrm{H} \times \mathrm{W}$ : height $\times$ width (for slot or crack) 


\section{AEROSOL TRANSPORT MODEL DEVELOPMENT}

\subsection{Introduction}

This section presents a phenomenological model of aerosol transport, deposition and plugging through capillaries, slots, and cracks. The model is based on the aerosol general dynamic equation and can simulate rough or smooth surfaces, irregular geometries, and unsteady flow. Four main deposition mechanisms (gravitational, Brownian diffusion, turbulent diffusion, and eddy impaction) have been included. Laminar, transition, and turbulent gas flow regimes have also been included in the model. The proposed model was tested and compared with experimental and theoretical work to evaluate its validity and identify its range of applicability, as described in Section 4. Overall, the model can predict important quantities such as plug mass, gas passed, plugging time, plug profile, and penetration fraction.

\subsection{General equations}

The principle of mass conservation is applied to describe aerosol transport in a container. The general mass balance requires:

rate of change of aerosol concentration $=$ inflow - outflow - deposition within container

For example, the principle of mass conservation when applied to aerosol particles inside a stainless steel canister is

$$
\frac{d C_{1}}{d t}=-\frac{Q C_{1}}{V_{1}}-\left(K_{1 g}+K_{1 d}\right) C_{1}
$$

where $\mathrm{C}_{1}$ is the particle concentration, $\mathrm{t}$ is time, $\mathrm{Q}$ is the volumetric flowrate, $\mathrm{V}_{1}$ is the canister's free volume, $K_{1 g}$ is the particle decay rate due to gravitational settling, and $K_{1 d}$ is the particle decay rate due to diffusion to the surfaces. The first term on the right side represents the rate at which particles are removed from the canister by airflow. The second term represents the rate at which particles are removed by deposition mechanisms on surfaces other than the stress corrosion crack. Outside the canister, mass balance requires

$$
\frac{d C_{2}}{d t}=\frac{P Q C_{1}}{V_{1}}-\frac{Q C_{2}}{V_{2}}-\left(K_{2 g}+K_{2 d}\right) C_{2}
$$

where $\mathrm{C}_{2}$ is the particle concentration outside the canister (e.g., overpack-canister gap), $\mathrm{P}$ is the penetration factor (i.e., the fraction of particle concentration leaving the canister and arriving outside), $\mathrm{K}_{2 \mathrm{~g}}$ is the particle decay rate due to gravitational settling, and $\mathrm{K}_{2 \mathrm{~d}}$ is the particle's decay rate due to deposition mechanism by diffusion. The penetration factor is typically derived empirically and calculated as the product of different deposition mechanisms. For example, if gravitational and diffusion depositions are the only mechanisms, then the penetration factor is

$$
P=P_{g} P_{d}
$$

where $\mathrm{P}_{\mathrm{g}}$ is the deposition due to gravitational diffusion, and $\mathrm{P}_{\mathrm{d}}$ is the deposition due to Brownian diffusion. Empirical penetration factors have been proposed [Mosley et al. 2001, Liu and Nazaroff 2003]. Alternatively, a more flexible and accurate way to calculate the particle deposition would be to use a phenomenological model as proposed herein.

\subsection{Gas flow modeling}

To describe gas flow in a leak path, a theoretical approach is used [Williams 1994]. This approach is simple and effective in capturing the essential features of the flow in a narrow leak path. Assuming 
isothermal flow, the flow field can be derived by solving the equations of continuity and momentum, which in one-dimensional steady-state form are as follows:

Continuity:

$$
\rho_{g} \mathrm{Au}=\mathrm{Q}_{m}
$$

Momentum:

$$
\rho_{g} u \frac{\mathrm{du}}{\mathrm{dx}}+\frac{\mathrm{dp}}{\mathrm{dx}}+2 \rho_{g} C_{f} \frac{u^{2}}{D_{H}}=0,
$$

where $\mathrm{C}_{\mathrm{f}}$ is the friction factor that depends mainly on Reynolds number. The fluid density $\rho_{\mathrm{g}}$ is related with the pressure $p$ and the temperature $T$ through the state equation $p=\rho \cdot R_{g} \cdot T$, where $R_{g}$ is the gas constant.

In practice, any temperature change would only have a small effect on gas flow, but it could provoke thermophoretic velocities that could affect aerosol deposition [Clement 1995]. The continuity and momentum equations given above can be applied to any cross sectional shape for which the hydraulic diameter is known. If the appropriate friction factor is known, then the equations are suitable for both laminar and turbulent flow. Using these equations, the mass flow rate $\mathrm{Q}_{\mathrm{m}}$ can be written as a function of the pressure drop along the flow direction:

$$
p_{u}^{2}-\mathrm{p}_{d}^{2}=\mathrm{R}_{g} \mathrm{TQ}_{m}^{2} \int_{0}^{L} C_{f}(\mathrm{Re}) \frac{\chi(x)}{A^{3}(x)} \mathrm{dx},
$$

where $\mathrm{x}$ is the axial distance from the inlet of the crack (or capillary), $\mathrm{p}_{\mathrm{u}}$ and $\mathrm{p}_{\mathrm{d}}$ are the pressure at the upstream and at the downstream of the crack, respectively, $\mathrm{L}$ is the length of the duct, $\chi$ is the perimeter of the duct, and $\mathrm{A}$ is the cross sectional area. This equation can be solved numerically to determine the mass flow rate $\mathrm{Q}_{\mathrm{m}}$. When this is known, the velocity and volume flow rate can be calculated using the mass continuity equation. Eq. (3) is validated for laminar and turbulent flow regions (see Section 4).

For constant cross section, Eq. (3) can be written in a simplified form:

$$
Q_{m}^{2}=\frac{A^{3}\left(p_{u}^{2}-\mathrm{p}_{d}^{2}\right)}{\chi C_{f} L \mathrm{R}_{g} \mathrm{~T}} .
$$

For laminar flow, the friction factor is

$$
C_{f}=\left\{\begin{array}{lr}
\frac{16}{R e}, & \text { cylindrical } \\
\frac{24}{R e}, & \text { rectangular }
\end{array},\right.
$$

where the Reynolds number is

$$
R e=\frac{4 Q_{m}}{\mu \chi}
$$

Substituting the friction factor $\mathrm{C}_{\mathrm{f}}$ and Reynolds number and assuming cylindrical geometry (capillary), 


$$
Q_{m}=\frac{\left(p_{u}^{2}-\mathrm{p}_{d}^{2}\right) \pi R^{3}}{16 \mathrm{R}_{g} \mathrm{~T} \mu \mathrm{L}}
$$

Similarly, for rectangular geometry such as slot or idealized crack,

$$
Q_{m}=\frac{\left(p_{u}^{2}-\mathrm{p}_{d}^{2}\right) w e^{3}}{24 \mathrm{R}_{g} \mathrm{~T} \mu \mathrm{L}}
$$

The transition from laminar to turbulent flow for pipes takes place at $\mathrm{Re}=2,300$. However, recent experiments with microcracks or capillary with micrometer diameters suggest that transition can occur much earlier, at Re numbers as low as 5-10 for rectangular geometries (Figure 1) and $\mathrm{Re}=400-600$ for cylindrical geometries (Figure 2). This results in the need for new friction factor correlations. Derived empirical correlations for friction factor at transition from laminar to turbulent flow regime are as follows:

for crack-like geometries and $\operatorname{Re}>5$ :

$$
C_{f}=0.25\left(\frac{2.11}{1+\log \left(R e^{1 / 2}\right)}\right)^{6.7683}
$$

for capillaries and $\operatorname{Re}>400$ :

$$
C_{f}=0.0025\left(5+\left(\frac{10^{6}}{R e}\right)^{1 / 3}\right) .
$$

These friction factors for transition to turbulent flow regime at low Reynolds numbers are used when validating the model presented in Section 4. 


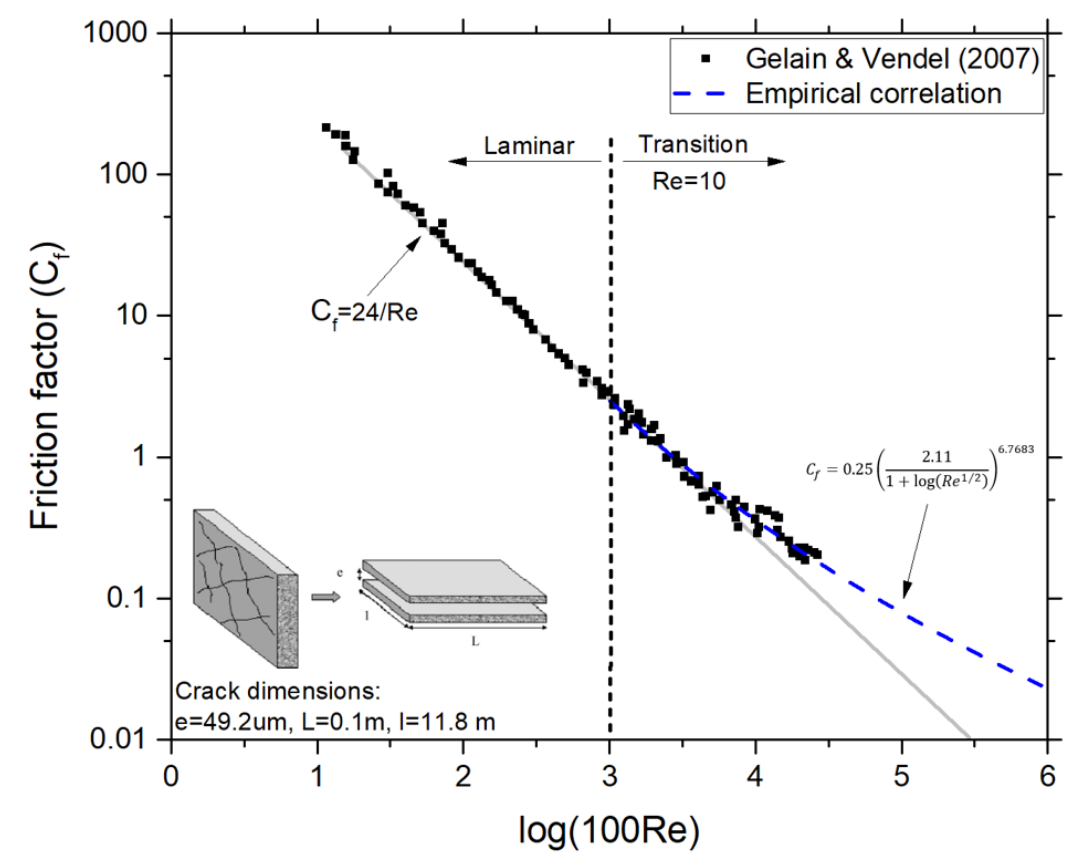

Figure 1. Friction factor vs. Reynolds number for crack-like geometries; the transition from laminar to turbulent flow occurs at $\mathbf{R e}=5-10$.

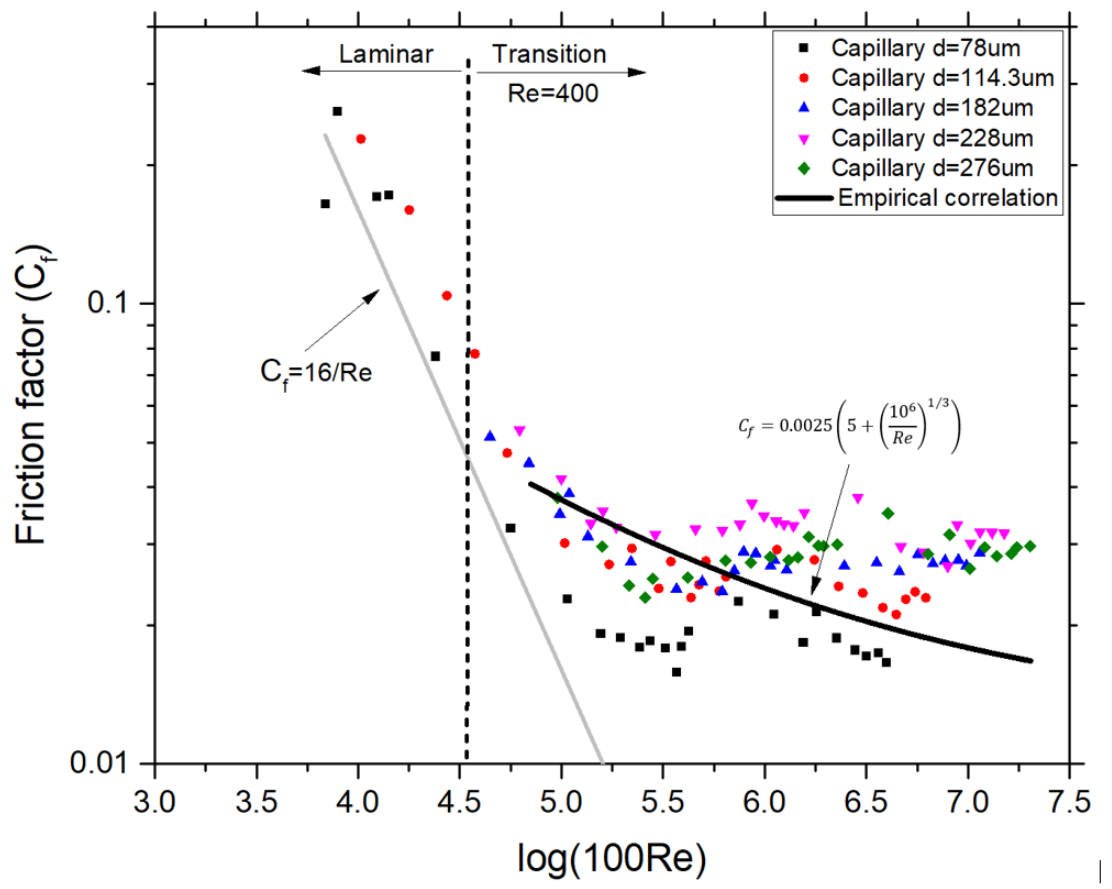

Figure 2. Friction factor vs. Reynolds number for capillaries; the transition from laminar to turbulent flow occurs at $\mathbf{R e}=\mathbf{4 0 0}$. 


\subsection{Aerosol transport and deposition}

The behavior of an aerosol within a volume may change due to processes that occur within it, processes referred to as internal, and due to process that transport particles actors the volume boundaries, referred to as external. Internal processes include coagulation, agglomeration, fragmentation and gas-to-particle conversions. Coagulation and agglomeration modify the size distribution without changing the mass concentration, whereas gas-to-particle conversion modifies the aerosol mascon concentration. External processes include transport across the boundaries due to gas flow, diffusion, particle motion included by temperature gradients, concentration gradients, gravitational settling and other external forces. All processes are described by a balance equation that is known as the general dynamic equations (GDE).

\subsubsection{Aerosol transport equation}

In the presence of a gas flow, the GDE in three-dimensional space becomes [Drossinos and Housiadas 2017]:

$$
\frac{\mathrm{dn}(\mathrm{r}, \mathrm{t})}{\mathrm{dt}}+\nabla \cdot(n \boldsymbol{u})=-\nabla \cdot\left(n \boldsymbol{v}^{e x t}\right)+\left.\frac{d n(\mathbf{r}, \mathrm{t})}{d t}\right|_{g-p}+\left.\frac{d n(\mathrm{r}, \mathrm{t})}{d t}\right|_{\text {coag }}
$$

where $n(r, t)$ is the number of particles per unit volume (number density), $\mathbf{u}$ is the gas flow velocity, $\mathbf{v}^{\text {ext }}$ is the deposition velocity due to external processes, and $g-p$ and coag refer to gas-to-particle conversion and coagulation internal processes. For the present model, internal processes can be neglected due to the fact that the transit time of the flow through the cracks is generally short.

With these simplifications, the GDE for the case of aerosol penetration through a crack is reduced to a transport equation, which can be written as follows in one-dimensional form:

$$
\frac{\mathrm{dC}(\mathrm{x}, \mathrm{t})}{\mathrm{dt}}+\frac{1}{A(\mathrm{x}, \mathrm{t})} \frac{d}{d x}[A(\mathrm{x}, \mathrm{t}) \cdot u(\mathrm{x}, \mathrm{t}) \cdot C(\mathrm{x}, \mathrm{t})]=-\mathrm{V}_{d}(\mathrm{x}, \mathrm{t}) \frac{\chi(\mathrm{x}, \mathrm{t})}{A(\mathrm{x}, \mathrm{t})} C(\mathrm{x}, \mathrm{t}),
$$

where $\mathrm{C}$ is the aerosol mass concentration, $\mathrm{V}_{\mathrm{d}}$ is the deposition velocity, $\mathrm{A}$ is the cross sectional area, $\chi$ is the wetted perimeter of the cross section and $u$ is the gas velocity. All previous parameters are functions of the axial coordinate $\mathrm{x}$ and time $\mathrm{t}$. The deposition velocity is calculated as the sum of the deposition velocities corresponding to each individual mechanism. In this paper, four deposition mechanics are considered: gravitational settling, Brownian diffusion, inertial impaction, and eddy impaction for the case of turbulent flow conditions. These deposition mechanisms are very common at the aerosol penetration investigation, and they also play a crucial role in aerosol retention.

\subsubsection{Deposition mechanisms}

The deposition velocities for the four main deposition mechanisms - gravitational settling, Brownian diffusion, turbulent diffusion, and eddy impaction—are described below.

Gravitational settling: The deposition velocity due to gravitational settling is written as [Drossinos and Housiadas 2017]:

$$
V_{d(s e d)}=\tau g \sin \theta,
$$

where:

$$
\tau=\frac{\rho_{p} d_{p}^{2} C_{c}}{18 \mu_{g}}
$$


Angle $\theta$ is the angle between the airway direction and the force of gravity (the so-called gravity angle), $\rho_{p}$ is the particle's density, $d_{p}$ is the particle's diameter, $C_{c}$ is the Cunningham slip correction factor that depends on the particle's size, $\mathrm{g}$ is the acceleration due to gravity, and $\mu_{\mathrm{g}}$ is the dynamic viscosity of the gas.

Brownian diffusion: The deposition velocity due to Brownian diffusion is determined using mass transfer theory. It is expressed in terms of the concentration boundary layer thickness, where according to the heat-mass transfer theory analogy, the Nusselt number is replaced by the Sherwood number Sh. Specifically:

$$
\begin{gathered}
V_{d(\text { diff })}=\frac{D_{B} S h}{D_{H}} \text {, and } \\
D_{B}=\frac{k_{B} T_{g} C_{C}}{3 \pi \mu_{g} d_{p}},
\end{gathered}
$$

where $\mathrm{D}_{\mathrm{H}}$ is the hydraulic diameter of the crack, and $\mathrm{D}_{\mathrm{B}}$ is the diffusion coefficient. The Sherwood number is specified as a function of distance from the beginning of the crack to properly account for entrance effects. The algebraic fittings used [Shah and London 1978] provide the local Sherwood number as a function of the dimensionless length $\mathrm{x}^{+}$, as follows:

$$
\begin{gathered}
x^{+}=\frac{x}{D_{H} \operatorname{ReSc}_{p}}, \\
\operatorname{Sh}\left(x^{+}\right)=\left\{\begin{array}{l}
1.077\left(x^{+}\right)^{\frac{-1}{3}}-0.7, \mathrm{x}^{+} \leq 0.01 \\
3.657+6.874\left(10^{3} x^{+}\right)^{-0.488} \exp \left(-57.2 \mathrm{x}^{+}\right), \mathrm{x}^{+}>0.01
\end{array} .\right.
\end{gathered}
$$

Inertial impaction: The deposition velocity due to inertial impaction is written as:

$$
V_{d(\text { inert-imp })}=u S t k D_{H} \pi / L_{c}
$$

where $u$ is the gas velocity and $L_{c}$ the length of the curved branching zone.

Turbulent diffusion: In case of turbulent flow, the mechanism of eddy diffusion is considered. Molecular (Brownian) diffusion can be neglected in this case. The deposition velocity due to eddy diffusion is determined by using the standard correlation given below [Wells and Chamberlain 1967]:

$$
V_{d(\text { turb-diff })}=0.2 u_{f r} S c_{p}^{-2 / 3} R e^{-1 / 8}, \tau^{+}<0.3 \text {, }
$$

where $\mathrm{u}_{\mathrm{fr}}$ is the friction velocity.

Eddy impaction: Eddy impaction comes into effect only when the flow is turbulent. In a turbulent fluid, there is an ensemble of eddies of varying size and intensity. Depending on their size and mass, particles tend to become entrained within the eddies and follow the eddies' motion. Eddy impaction velocity will be written in terms of friction velocity $u_{\mathrm{fr}}$ and reduced stopping time $\tau^{+}$, as follows [Drossinos and Housiadas 2017]:

$$
V_{d(\mathrm{turb})}=\min \left[6 \times 10^{-4}\left(\tau^{+}\right)^{2} u_{f r}, 0,1 u_{f r}\right], \tau^{+}>0.3
$$


Total deposition velocity: The total deposition velocity is given as the algebraic sum of the deposition velocities corresponding to each individual mechanism described previously, namely:

$$
V_{d}=\left\{\begin{array}{cc}
V_{d(\text { sed })}+V_{d(\text { diff })}+V_{d(\text { inert-imp })} & \text { (laminar flow }), \\
V_{d(\text { sed })}+V_{d(\text { eddy-imp })}+V_{d(\text { turb-diff })}+V_{d(\text { inert-imp })} & \text { (turbulent flow }) .
\end{array}\right.
$$

The implicit assumption permitting the algebraic addition of the individual velocities is that the deposition mechanisms are independent of each other.

\subsection{Plugging}

A leak path through which aerosol passes may become plugged. The particulate matter will deposit on the surface, changing the internal geometry of the flow area. Eventually the plug mass will increase and will lead to a complete obstruction of the pathway. There is experimental evidence that other possibilities also exist, such as rebound of particles or plug fragmentation [Morton and Mitchell 1995] at some stage in the deposition progress. The present analysis is limited to addressing the case of a continuous build-up of deposits until the path is completely plugged. The mass of the deposit up to any position $\mathrm{S}$ can be obtained in terms of the deposition velocity and the particle concentration, as follows:

$$
M_{d e p}=\int_{0}^{S} \int_{0}^{t} 2 \pi R C V_{d} d x d t
$$

Assuming that the deposit material is homogeneous with a density equal to the density of the particles, then the volume of the deposit can be directly derived from its mass:

$$
V_{\text {dep }}=\frac{M_{d e p}}{\rho_{p}} \text {. }
$$

In Eq. (26) above, density $\rho_{\mathrm{p}}$ is assumed to be the bulk material density. This approximation is more accurate for large particles that are deposited mainly by gravity or eddy impaction. The deposition of particles is assumed to occur uniformly on the path's circumference. This assumption is valid for mechanisms such as diffusion (Brownian or turbulent) or eddy impaction, but it is approximate for directional mechanisms such as gravitational settling. Under this assumption, the change in radius due to plugging is related to the deposit volume, as follows:

$$
d R=\frac{1}{2 \pi R} \frac{d V_{d e p}}{d x} .
$$

\subsection{Numerical solver}

A diagram describing the numerical solution algorithm is shown in Figure 3. As described above, the numerical solution first calculates the fluid velocity in each time step. Then the particle transport equation, Eq. (14), is solved using an implicit finite difference scheme. The upwind scheme is used for the discretization of the convection term, which is the second term on the left-hand side of Eq. (14). The duct radius is then updated according to Eq. (27) through calculating the amount of the deposited mass, as shown in Eqs. (25) and (26). All the numerical integrations required in this calculation are performed using the trapezoidal rule. The new cross section is then used for the aerosol calculations in the next step. 


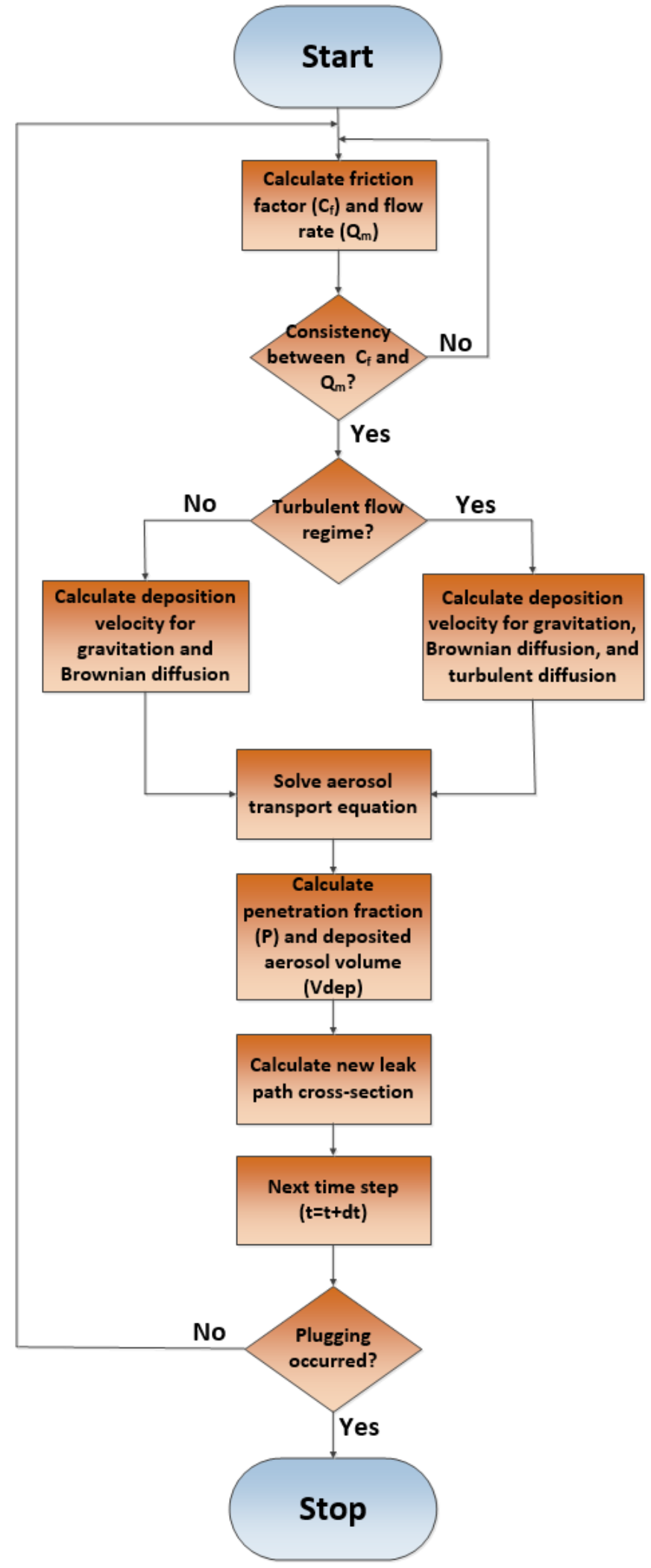

Figure 3. Block diagram for numerical solution of the aerosol transport equation. 


\section{VALIDATION}

To illustrate and evaluate the proposed aerosol transport model, the model was benchmarked against real experimental cases of particle penetration and plugging in leak paths under a variety of conditions in tubes or real cracks. Three distinctive, independent types of experiments were used for this purpose. The first refers to the flow rate experiments in cracks [Gelain and Vendel 2007] and capillaries [Sutter et al. 1979]. The second and third experiments are focused on penetration of particles through the cracks of a naturally broken brick [Liu and Nazaroff 2003] and on penetration of particles through a cracked reinforced concrete sample [Gelain and Vendel 2007].

\subsection{Flow rate benchmarking}

Deposition mechanisms depend on flow rate, so the ability to correctly predict flow rate is critical to this work. To evaluate the flow rate prediction capabilities of the proposed model, two experiments were used: one in rectangular (crack-like) geometries [Gelain and Vendel 2007], and one in capillaries of various diameters [Sutter et al. 1979]. The results of the models vs. experimental measurements are shown in Figures 4-7. The transition from laminar to turbulent flow regime and the subsequent change in flow rate can be seen in Figures 4 and 5. The friction factors described in Section 3 for laminar and transition flow regimes were used. The following observations are made:

- The numerical model correctly predicts both the flowrates and Reynolds numbers for various pressure differences in laminar and transition flow regimes.

- For rectangular geometries, transition to turbulent flow regime starts at $\mathrm{Re}=5-10$. For cylindrical geometries, transition to turbulent flow regime starts at $\mathrm{Re}=400$. This is contrary to the widely used $\mathrm{Re}=2300-4000$.

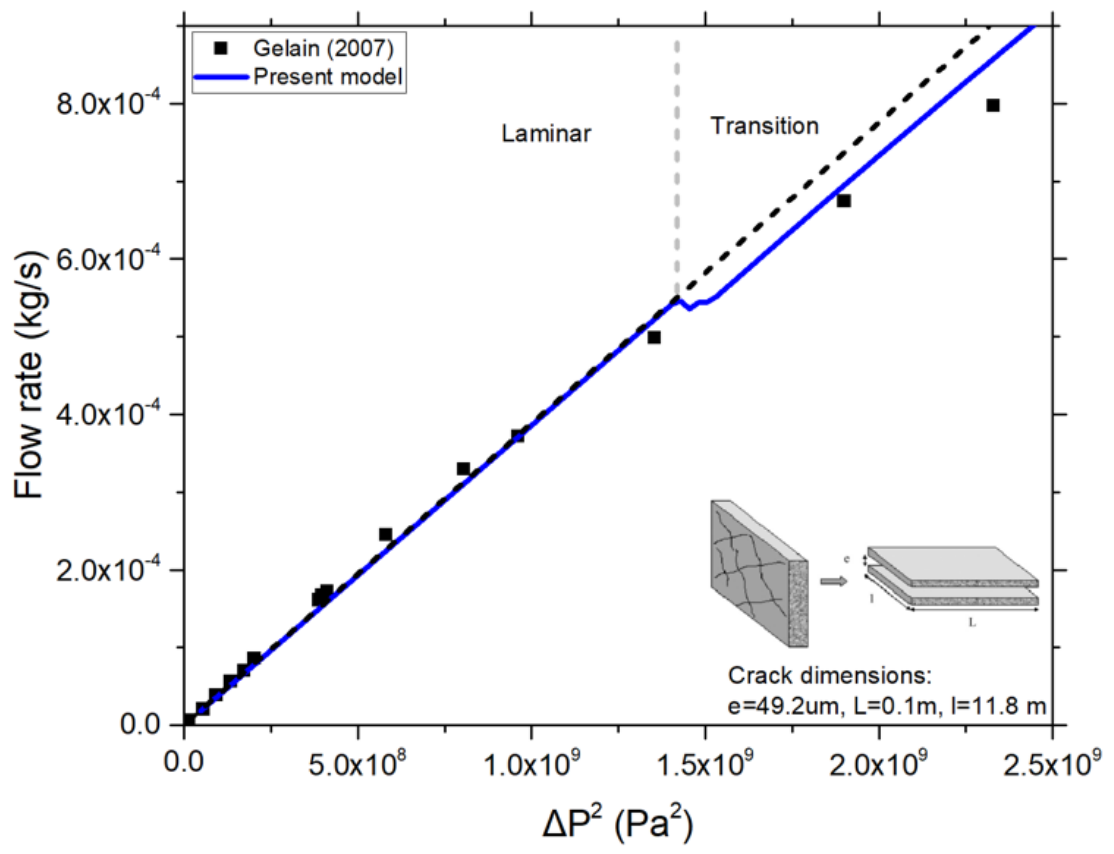

Figure 4. Flow rate vs. pressure difference for rectangular geometry [Sutter et al.]. 


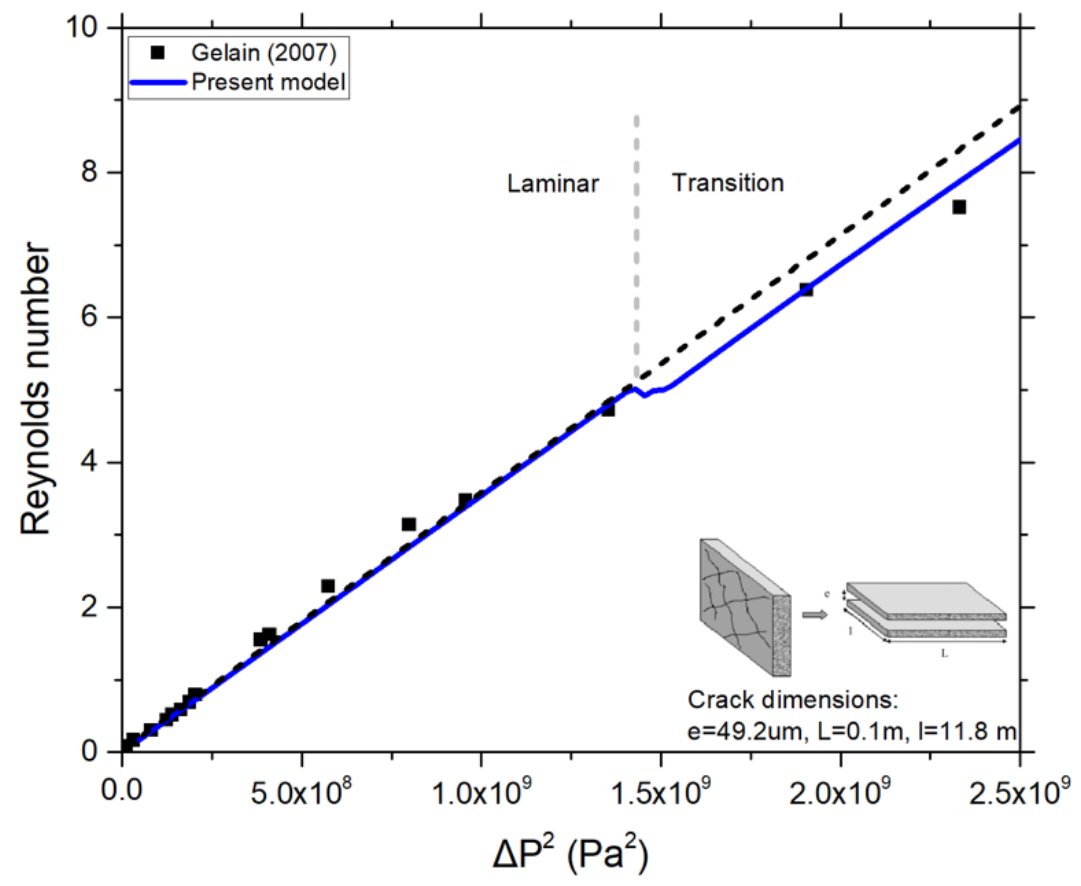

Figure 5. Reynolds number vs. pressure difference for rectangular geometry [Sutter et al.].

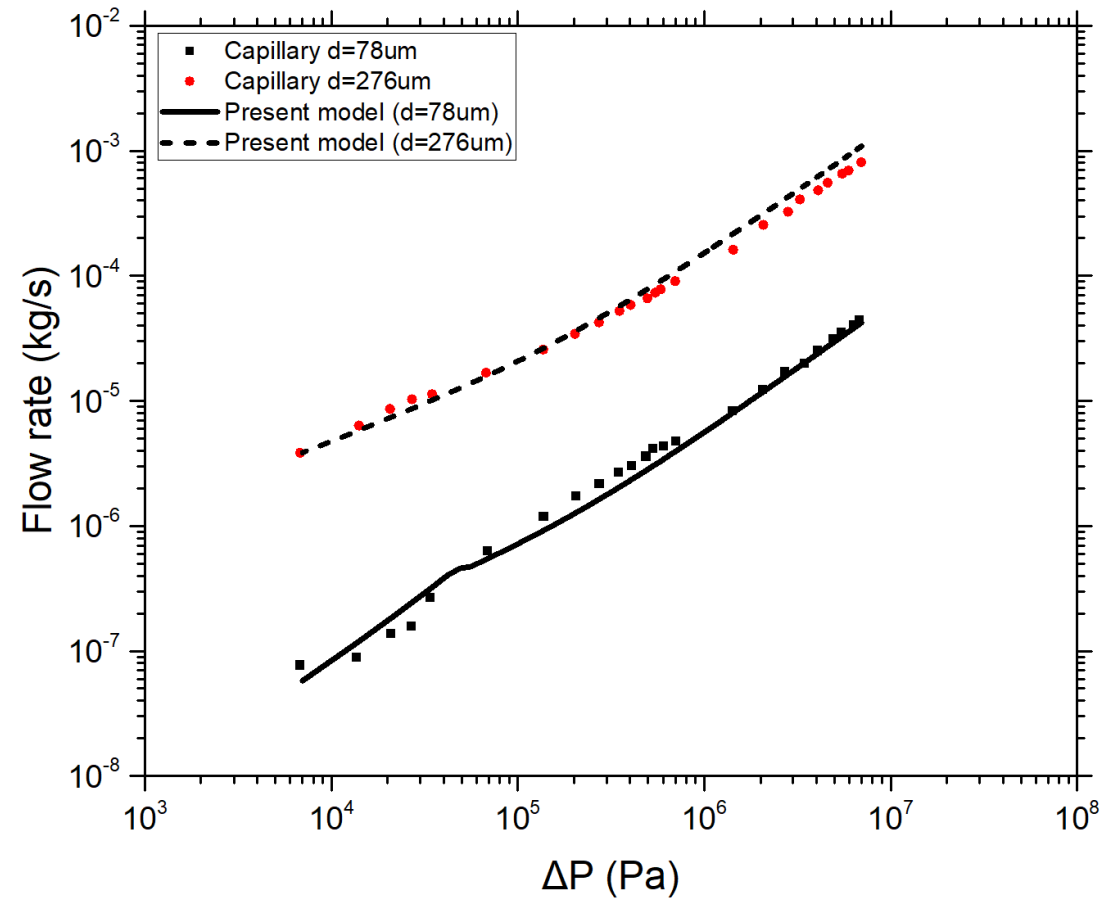

Figure 6. Flow rate vs. pressure difference for cylindrical geometry [Sutter et al.]. 


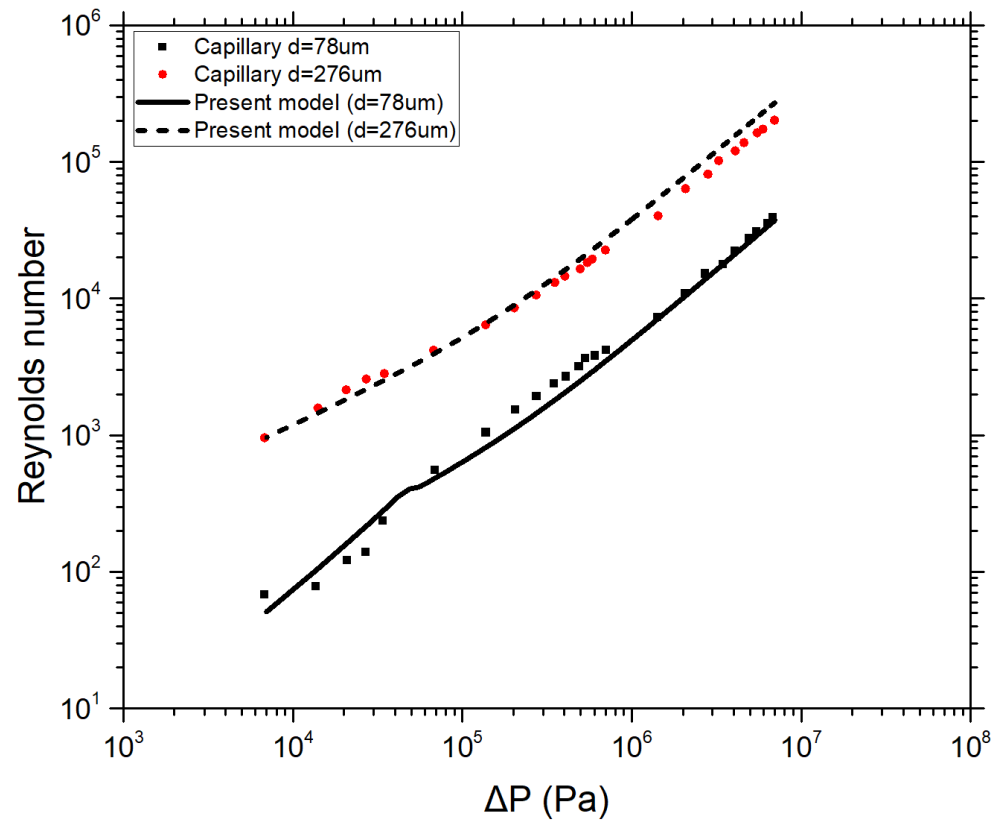

Figure 7. Reynolds number vs. pressure difference for cylindrical geometry [Sutter et al.].

\subsection{Comparison with empirical model by Gelain and Vendel (2007)}

Gelain and Vendel (2007) used available deposition diffusion, gravitational settling, and impaction empirical models to develop a holistic deposition model suitable for rectangular channel geometries. The model was subsequently compared against experimental measurements in rectangular cracks. Gelain and Vendel (2007) used the retained fraction to represent their model, $F r$ :

$$
F r=1-\frac{C_{2}}{C_{1}}
$$

where $\mathrm{C}_{1}$ and $\mathrm{C}_{2}$ are the upstream and downstream aerosol mass concentrations. The diffusional deposition model proposed by Bowen (1967) was considered:

$$
\begin{aligned}
F r_{\text {diffusion }}=1 & -\left(0.9104 e^{-2.8278 \theta}+0.0531 e^{-32.147 \theta}+0.01528 e^{-93.475 \theta}\right. \\
& \left.+0.00681 e^{-186.805 \theta}\right)
\end{aligned}
$$

where parameter $\theta$ is:

$$
\theta=\frac{8 D_{B} L l}{3 Q e} .
$$

The following gravitational settling model was considered (Fuchs 1964):

$$
F r_{\text {settling }}=\frac{V_{\text {settling }} L}{u e}
$$

where $V_{\text {settling }}$ is:

$$
V_{\text {settling }}=\frac{\rho_{p} d_{p}^{2} C_{C}}{18 \mu} g
$$


A model by Regtuit et al. (1990) was used to describe inertial impaction:

$$
F r_{\text {impaction }}=1-\frac{1}{1+a S t k^{b}} \text {. }
$$

In this model, $a=85.88$ and $b=1.24$ are constants determined by a chi-square minimization between experimental data. Stk is the Stokes number:

$$
S t k=\frac{\rho_{p} d_{p}^{2} u}{18 \mu e} .
$$

Gelain and Vendel (2007) proposed the following coupling of the above models to represent the total aerosol deposition in a rectangular channel:

$$
F r_{\text {total }}=1-\prod_{i}\left(1-F r_{i}\right) .
$$

where $F r$ is the retained fraction for the global model, $F r_{i}$ is the retained fraction for the phenomenon $i$, and $i$ is the different phenomena (diffusion, sedimentation and inertial impaction).

The present numerical model (described in Section 3) is compared with the model of Gelain and Vendel (2007) as a function of mass flow rate and for different particle diameters $(60 \mathrm{~nm}, 0.8 \mu \mathrm{m}, 1.1 \mu \mathrm{m}$, and $4.1 \mu \mathrm{m})$. The simulated rectangular channel geometry was the same as the one used by Gelain and Vendel (2007), $49.2 \mu \mathrm{m} \times 11.8 \mathrm{~m} \times 0.1 \mathrm{~m}$. The comparison is shown in Figures 8-11. Good agreement is observed between the two models. The following observations are made:

- Diffusion governs the deposition of particles with $d_{p}=60 \mathrm{~nm}$. For particles with very low diameter, gravitational and inertial impaction are practically negligible.

- Inertial deposition in the high flow rate regime and gravitational settling in the low flow rate regime govern the deposition for particles having diameter $d_{p}>1 \mu \mathrm{m}$. Diffusion is negligible in that range.

- The numerical model underestimates the particle deposition by $5-10 \%$ for $\mathrm{d}_{\mathrm{p}}=60 \mathrm{~nm}$ when compared with the model of Gelain and Vendel (2007). However, good agreement is observed for $\mathrm{d}_{\mathrm{p}}>1 \mu \mathrm{m}$.

- For particles with diameters close to $1 \mu \mathrm{m}$ the deposition is strongly dependent on the flow rate and particle diameter. There is a minimum in the retained fraction that increases with increasing particle diameter. For a smaller or larger flow rate the retained fraction increases until it reaches 1.0. For very small flow rates close to zero, gravitation settling dominates. For larger flow rates, inertial impaction dominates. The result is that for either very small or very large flow rates, no aerosol penetration will occur.

- The numerical model provides a more realistic deposition ratio for low flow rate. In this regime and for particles with $d_{p}>1 \mu \mathrm{m}$, the model of Gelain and Vendel (2007) predicts deposition that is larger than 1.0, which is not possible.

- All particles having diameter $\mathrm{d}_{\mathrm{p}}>4 \mu \mathrm{m}$ would be retained, i.e., no penetration, within the channel independent of flow rate. 


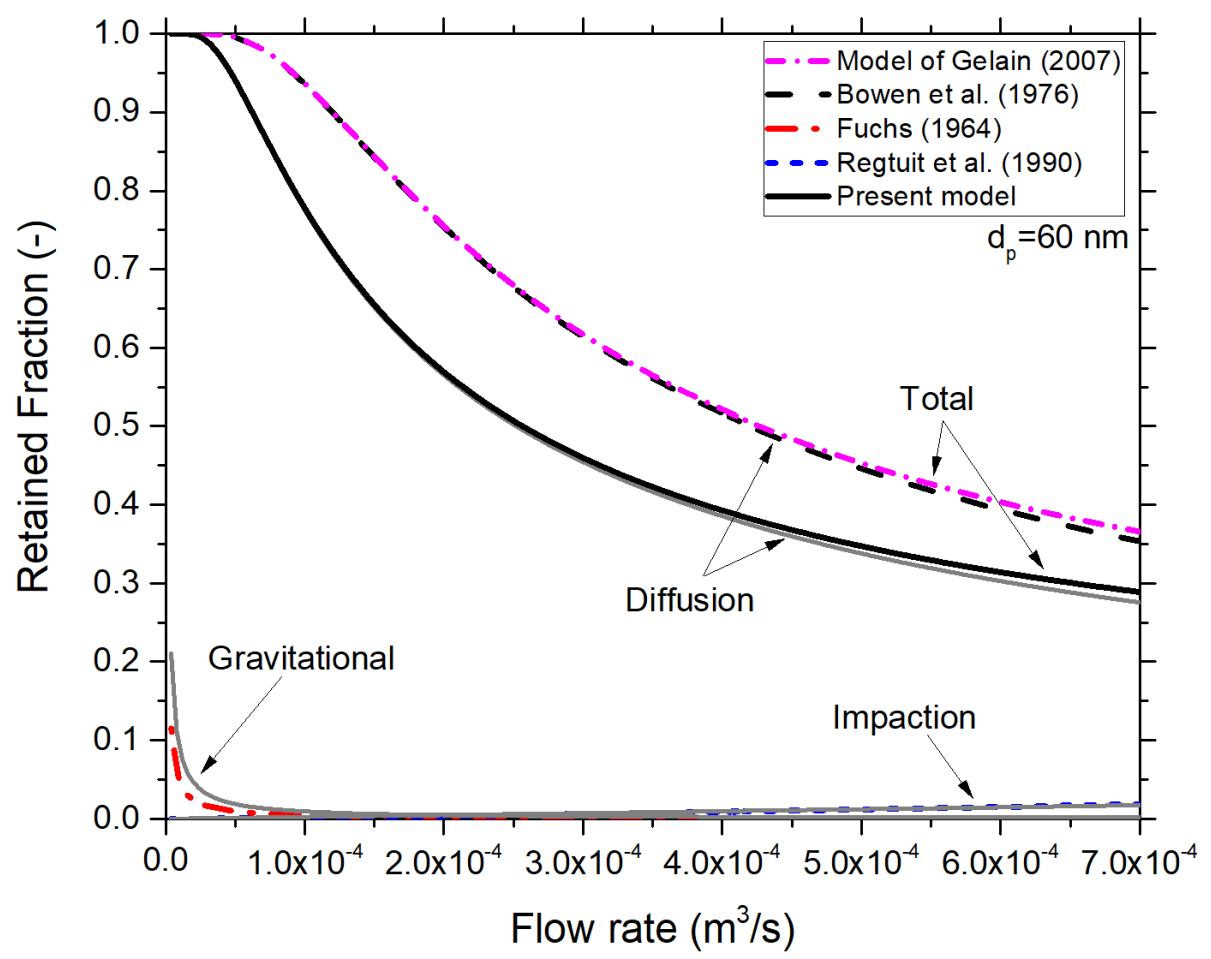

Figure 8. Retained fraction of particles with $d_{p}=60 \mathrm{~nm}$ as a function of flow rate.

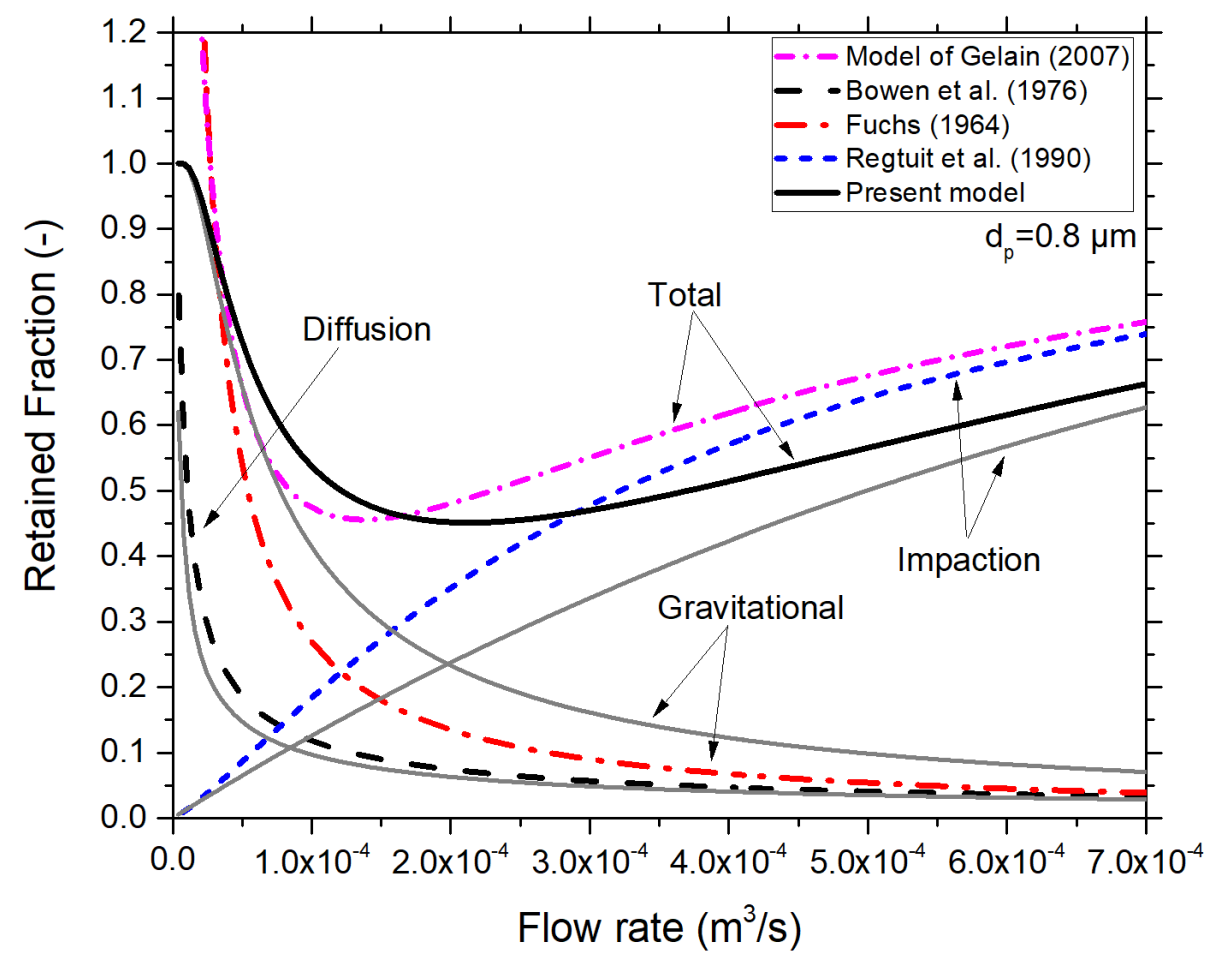

Figure 9. Retained fraction of particles with $d_{p}=0.8 \mu \mathrm{m}$ as a function of flow rate. 


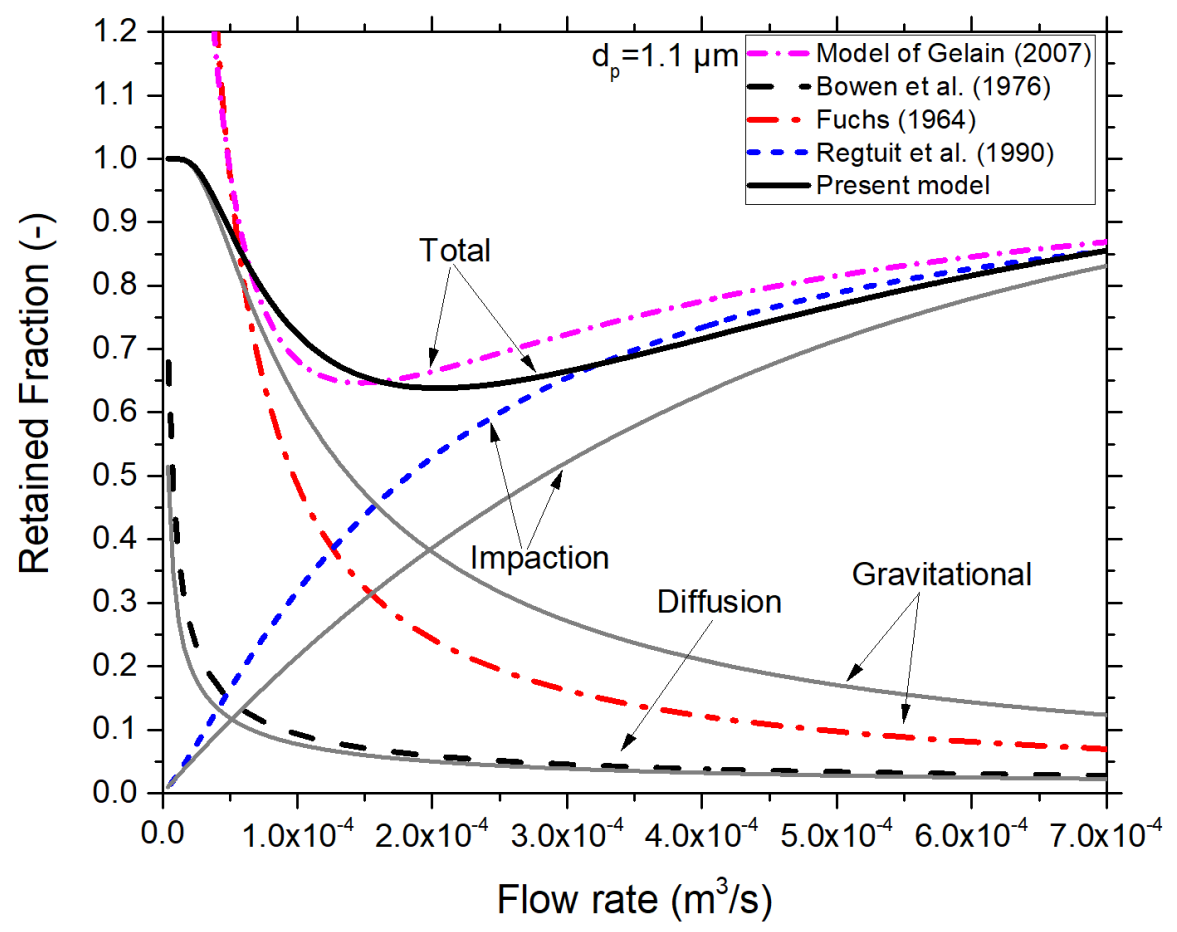

Figure 10. Retained fraction of particles with $d_{p}=1.1 \mu \mathrm{m}$ as a function of flow rate.

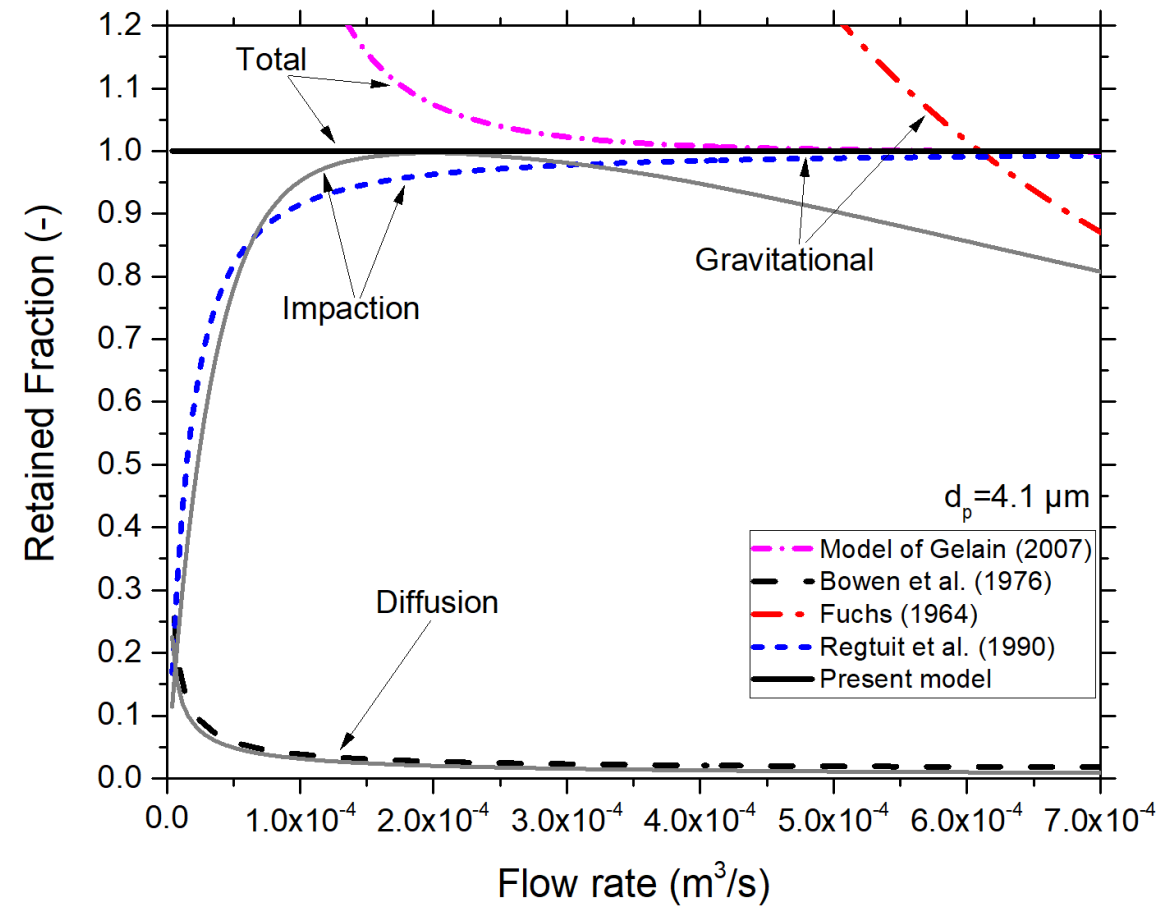

Figure 11. Retained fraction of particles with $d_{p}=4.1 \mu \mathrm{m}$ as a function of flow rate. 


\subsection{Comparison with experiments by Liu and Nazaroff (2003)}

Liu and Nazaroff (2003) experimentally studied the penetration of particles through cracks of usual building materials. They used cracks of well-defined, controlled geometry by machining the materials samples, but they also created real cracks by breaking a brick. Results from the latter tests were selected in the present work to imitate a realistic case. The test conditions refer to a nominal leak path length of $4.5 \mathrm{~cm}$, crack heights of 0.25 and $1 \mathrm{~mm}$, and a pressure difference of $4 \mathrm{~Pa}$. The authors measured the particle penetration fraction for particle sizes $0.02-7 \mu \mathrm{m}$. Figure 12 shows the penetration fraction of particles for two different crack heights as calculated with our numerical model and compares the calculated results with the measured data. The flow was laminar, so only two deposition mechanisms are accounted for in the calculations in this work: namely Brownian diffusion and gravitational settling. The calculated results from the global model of Gelain (2007) are also shown. The following observations are made:

- As seen in Figure 12, the model created for this work provides satisfactory results as compared with the measured data of Liu and Nazaroff.

- Generally, both models display similar performances, but the penetration fraction as calculated with the model of Gelain (2007) underpredicts when crack height is $1 \mathrm{~mm}$ and overpredicts when crack height is $0.25 \mathrm{~mm}$.

- The model of Gelain (2007) goes abruptly to zero for large particles in the $0.25 \mathrm{~mm}$ case. The model developed for the current effort predicts that the penetration fraction will asymptotically reach zero, a behavior which is more consistent with the measured data.

- Overall, it is observed that particles with $\mathrm{d}_{\mathrm{p}}<0.01 \mu \mathrm{m}$ or $\mathrm{d}_{\mathrm{p}}>4 \mu \mathrm{m}$ will not penetrate a crack with a height less than $250 \mu \mathrm{m}$. This is in agreement with the results from Gelain and Vendel (2007).

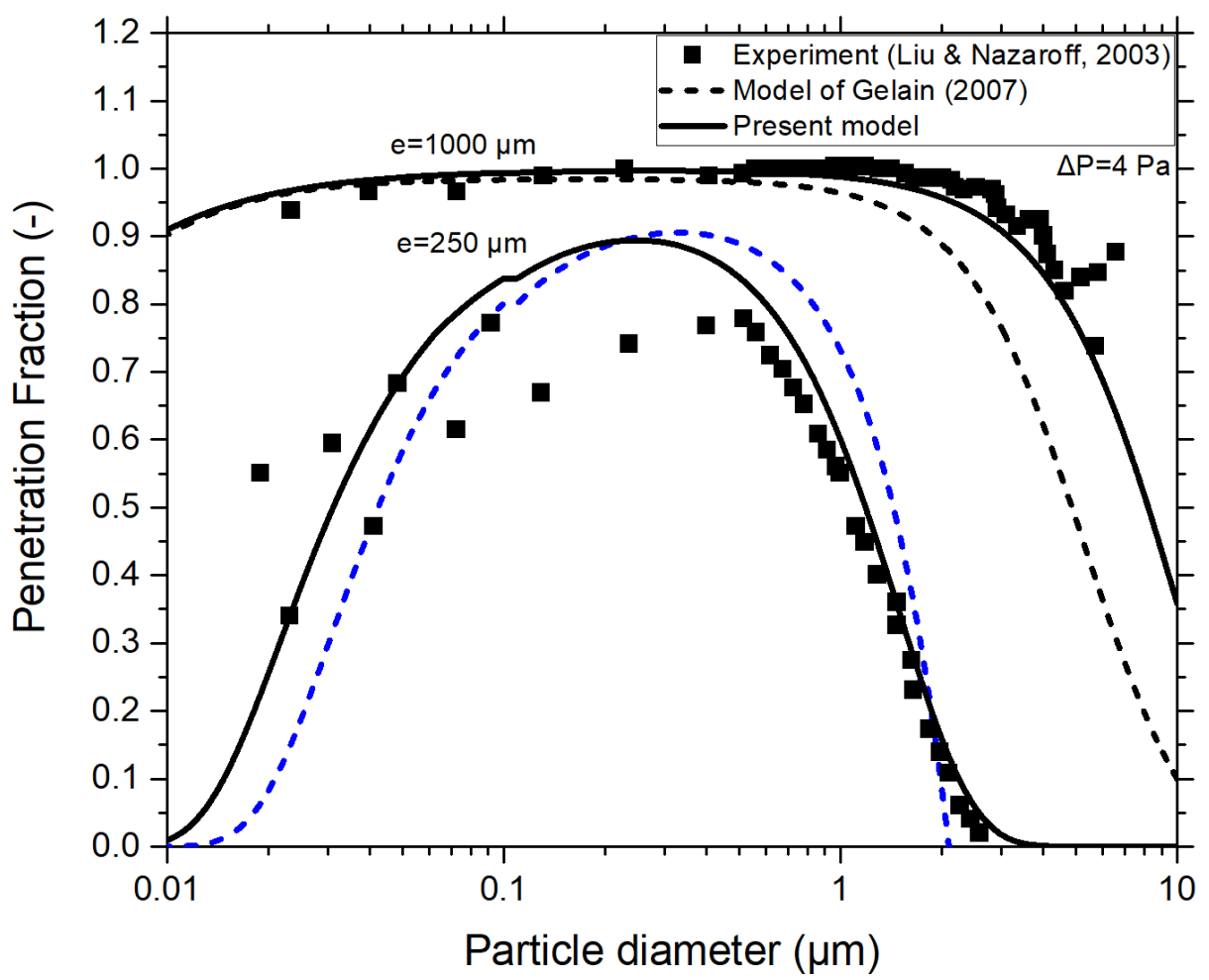

Figure 12. Penetration fraction of particles as a function of particle diameter. 


\subsection{Comparison with experiments by Gelain \& Vendel (2007)}

The experiments performed by Gelain and Vendel $(2006,2007)$ concern the penetration of particle through a real crack network that was created in a reinforced concrete slab measuring $128 \mathrm{~cm} \times 75 \mathrm{~cm} \times 10 \mathrm{~cm}$. The sample wall was cracked by subjecting it to shear stresses from alternate directions. The tests were performed with monodisperse aerosols with particles between $50 \mathrm{~nm}$ and $4 \mu \mathrm{m}$. The aerosol penetration fraction was measured as a function of the imposed pressure difference across the concrete slab as a function of the flowrate leaking through the crack network. With the coarse particles of $4 \mu \mathrm{m}$, the aerosol was completely trapped in the cracks. The results for the $1 \mu \mathrm{m}$ aerosol diameter have shown a partial retention. Figures 13-16 show the penetration fraction of particles as calculated with the model developed for this effort and compares the calculated results with the measured data. The following observations are made:

- The present model gives satisfactory results when compared with the experimental measurements of Gelain and Vendel, and it is also in close agreement with their model. Generally, both models display similar performances.

- The present model gives a more realistic prediction for low flow rates. The model of Gelain (2007) predicts values higher than 1.0. The model developed for the current effort predicts that the penetration fraction will asymptotically reach 1.0, a behavior which is more consistent with the measured data.

- All particles having diameter of $\mathrm{d}_{\mathrm{p}}=4.1 \mu \mathrm{m}$ are retained, i.e., no penetration, within the channel independent of flow rate.

- Particles of several microns can hardly penetrate through cracks because of the highly efficient removal of such particles by interaction deposition or gravitational settling. 


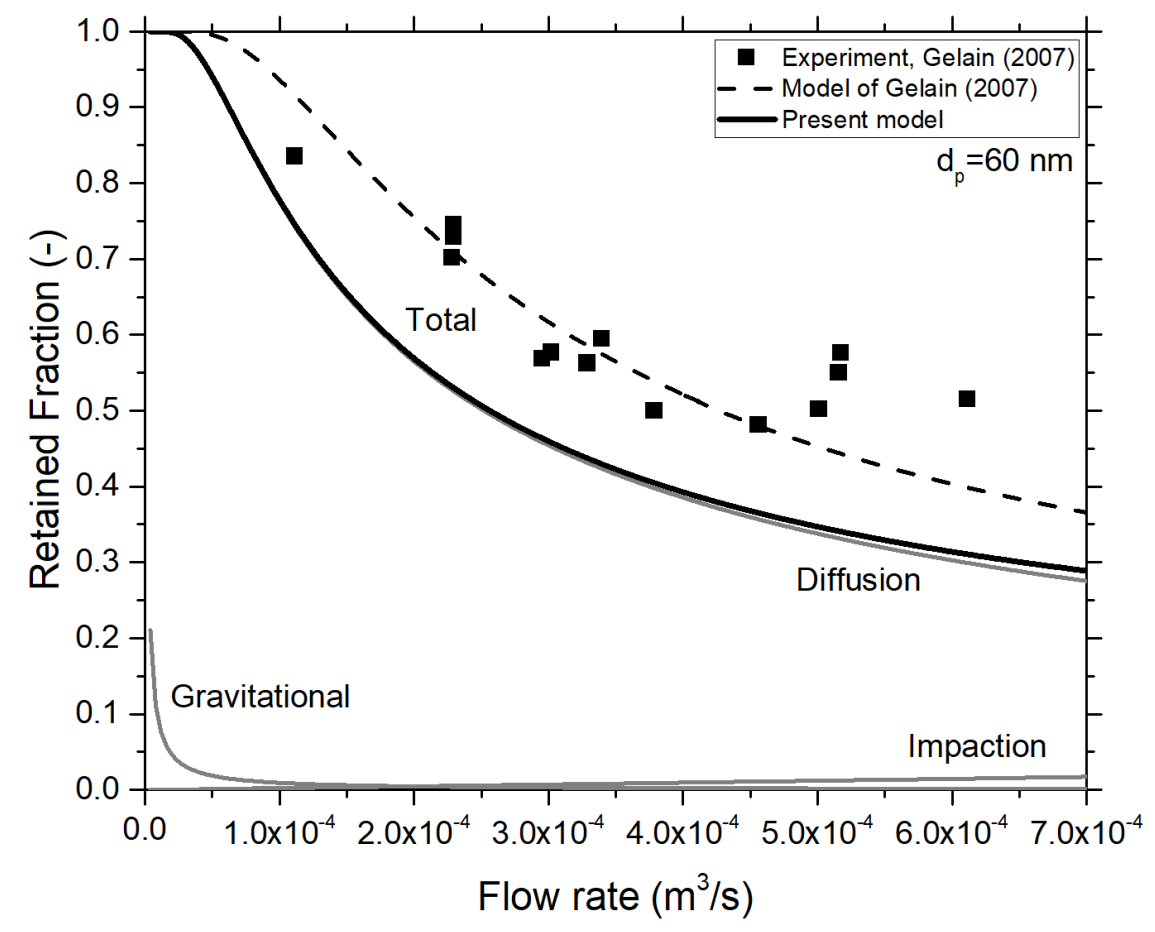

Figure 13. Deposition fractions for particles of aerodynamic diameter of $60 \mathrm{~nm}$.

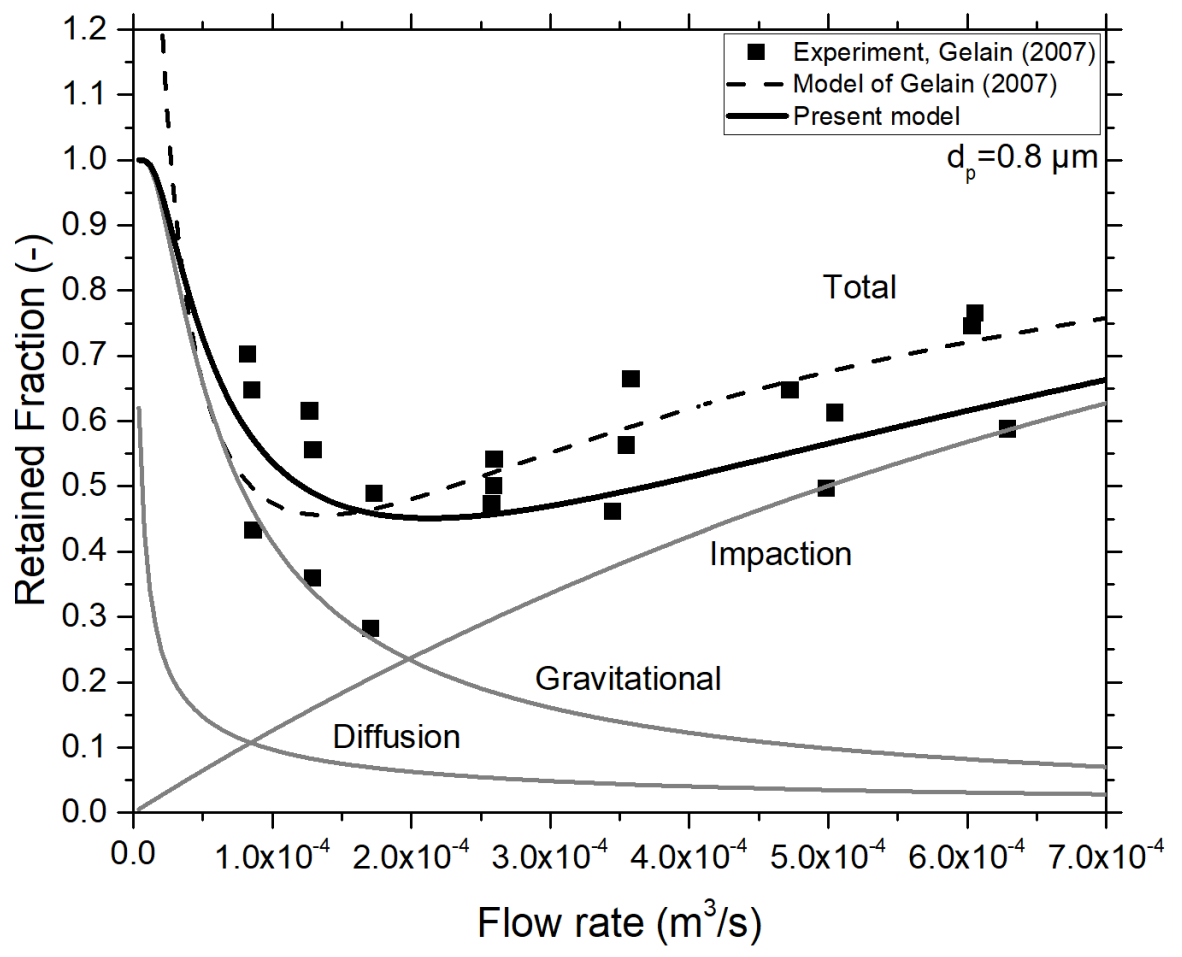

Figure 14. Deposition fractions for particles of aerodynamic diameter of $0.8 \mu \mathrm{m}$. 


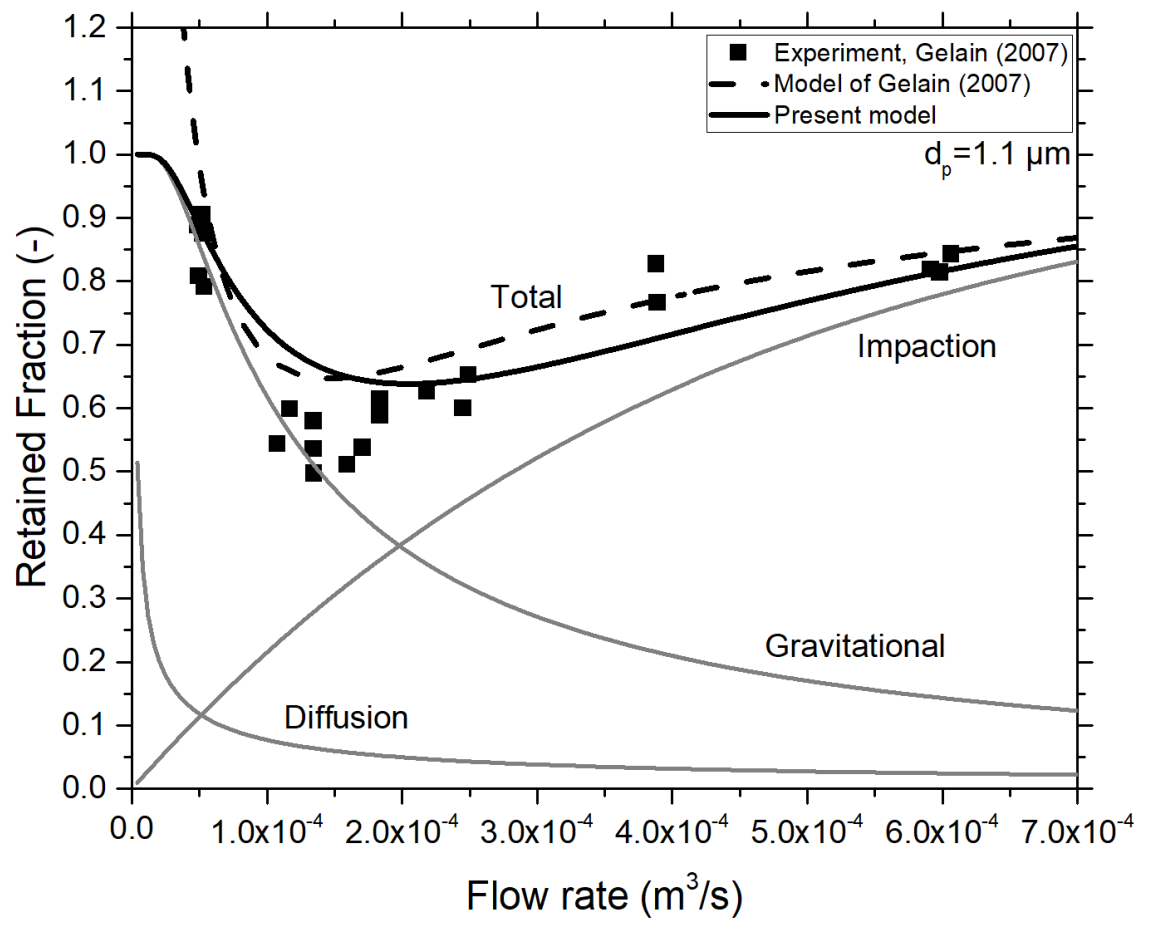

Figure 15. Deposition fractions for particles of aerodynamic diameter of $1.1 \mu \mathrm{m}$.

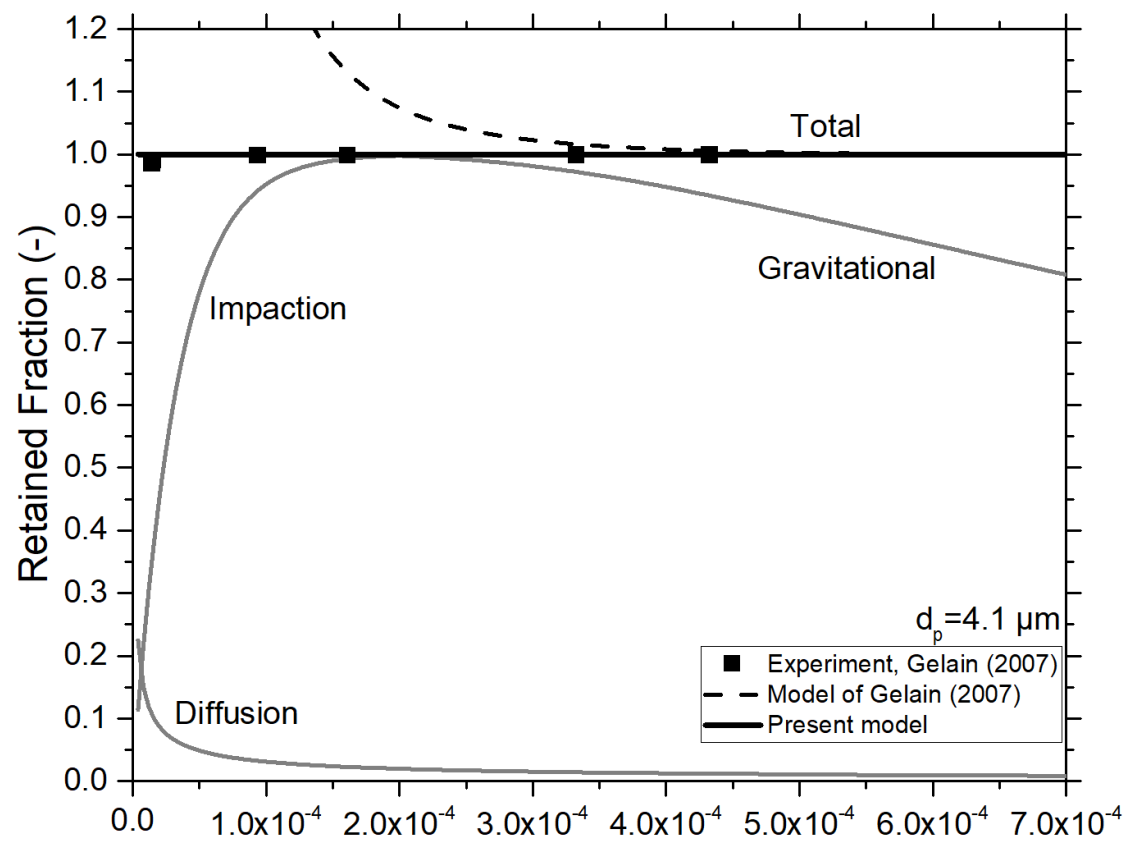

Flow rate $\left(\mathrm{m}^{3} / \mathrm{s}\right)$

Figure 16. Deposition fractions for particles of aerodynamic diameter of $4.1 \mu \mathrm{m}$. 


\section{RESULTS AND DISCUSSION}

Particle penetration through CISCC cracks was estimated using the validated numerical model and by considering the effects of three major deposition mechanisms (see Section 3): diffusion, gravitational settling, and inertial impaction. Particles are assumed to be spherical with a density of $8 \mathrm{~g} / \mathrm{cm}^{3}$ and with diameters ranging from 0.001 to $10 \mu \mathrm{m}$. The particle density was selected to represent particles with similar densities that may be released within a canister, e.g., Co-60 from CRUD or $\mathrm{UO}_{2}$ particles from fuel pellets. We assume a uniform crack geometry throughout the channel, smooth inner surface and steady airflow through the crack. Three crack heights (crack opening) were selected, $\mathrm{e}=30 \mu \mathrm{m}, \mathrm{e}=50 \mu \mathrm{m}$, and $\mathrm{e}=100 \mu \mathrm{m}$. Crack width was $10 \mathrm{~mm}$ and crack length $1.27 \mathrm{~cm}(0.5 \mathrm{in}$.). These dimensions are representative of real CISCC cracks. In this case, the width of the crack in the third dimension is much larger than crack opening so that airflow can be reasonable modeled as two dimensional without loss of generality. It is noted that in real cracks, irregular geometry and surface roughness might increase particle deposition significantly. However, this issue would be best explored by laboratory scale experimental studies.

Figure 17 shows predicted particle penetration factor as a function of particle diameter and crack opening for pressure difference $\Delta \mathrm{P}=10 \mathrm{~Pa}$. Pressure difference less than $10 \mathrm{~Pa}$ would be expected between canister pressure and ambient environment following canister depressurization. Figure 18 shows particle penetration fractions for a crack height of $30 \mu \mathrm{m}$ and three pressure differences $\Delta \mathrm{P}=50 \mathrm{~Pa}, 100 \mathrm{~Pa}$, and $200 \mathrm{~Pa}$. These higher pressure differences were selected to better understand the required pressure that will allow significant particle penetration from such a small microcrack. The following observations can be made:

- The results in Figure 17 suggest that particles having diameters in the range 0.1-0.5 $\mu \mathrm{m}$ have the highest penetration across the whole particle spectrum. This is in agreement with earlier results (see Section 4). Larger and smaller particles are readily removed in cracks under the gravitation settling and diffusion, respectively.

- As indicated in Figure 17, the penetration factor becomes negligible for particles with diameters larger than $1 \mu \mathrm{m}$ even when crack opening is $100 \mu \mathrm{m}$.

- For crack height $50 \mu \mathrm{m}$, particle penetration fraction is less than $30 \%$. At crack height $100 \mu \mathrm{m}$ penetration is less than $90 \%$. This translates in a reduction factor of 3 although crack height decreased by a factor of 2 .

- For crack heights less than $30 \mu \mathrm{m}$, penetration is practically zero. This indicates that penetration varies strongly with crack height and is significantly reduces with smaller crack heights.

- Figure 18 shows that significant pressure difference is needed, larger than $50 \mathrm{~Pa}$, for considerable penetration to occur from a $30 \mu \mathrm{m}$ crack. Even when $\Delta \mathrm{P}=200 \mathrm{~Pa}$, penetration is less than $60 \%$. For $\Delta \mathrm{P}=50 \mathrm{~Pa}$, penetration is less than $20 \%$ and practically zero for smaller pressure difference.

- Figure 19 shows regimes for aerosol transport through CISCC cracks as a function of pressure difference. Practically no aerosol release is predicted for cracks with opening displacement ("height") less than $50 \mu \mathrm{m}$ when ambient conditions prevail. Further, no particles with diameter $>1 \mu \mathrm{m}$ will be released for cracks with opening displacement ("height") less than $100 \mu \mathrm{m}$. 


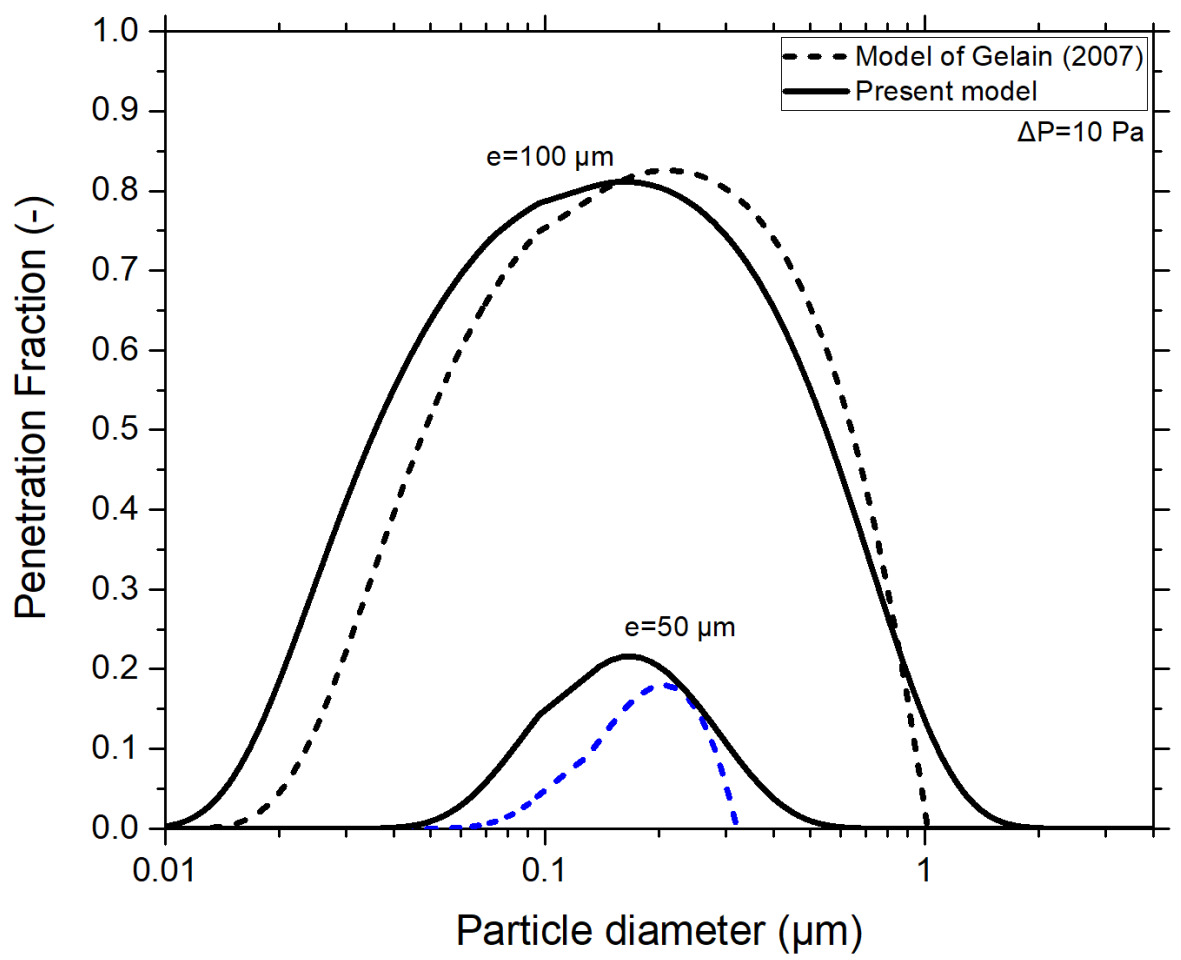

Figure 17. Penetration fraction as a function of particle diameter for two crack heights, $\mathrm{e}=50 \mu \mathrm{m}$ and $\mathrm{e}=100 \mu \mathrm{m}$, and $\Delta \mathrm{P}=10 \mathrm{~Pa}$.

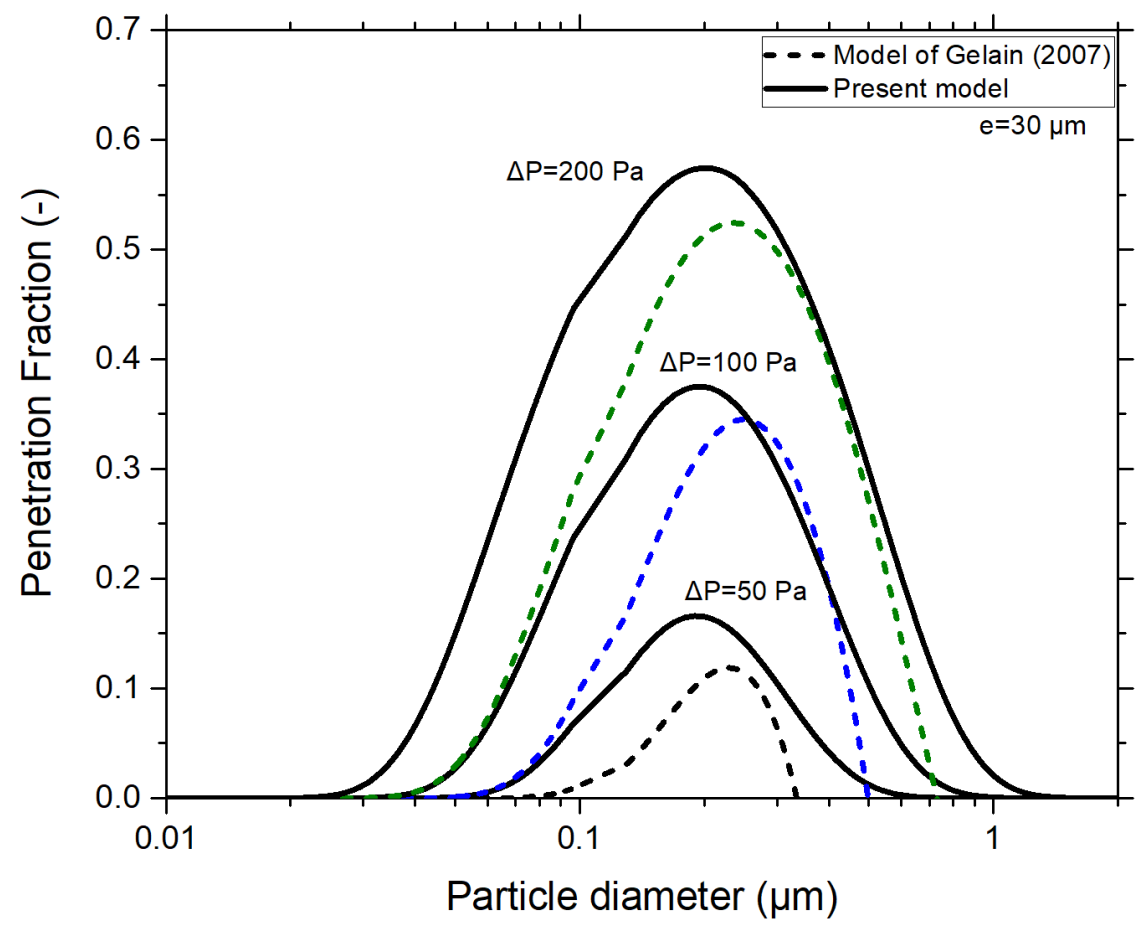

Figure 18. Penetration fraction as a function of particle diameter for crack height $\mathrm{e}=30 \mu \mathrm{m}$ and $\Delta \mathrm{P}=50 \mathrm{~Pa}, 100 \mathrm{~Pa}$, and $200 \mathrm{~Pa}$. 


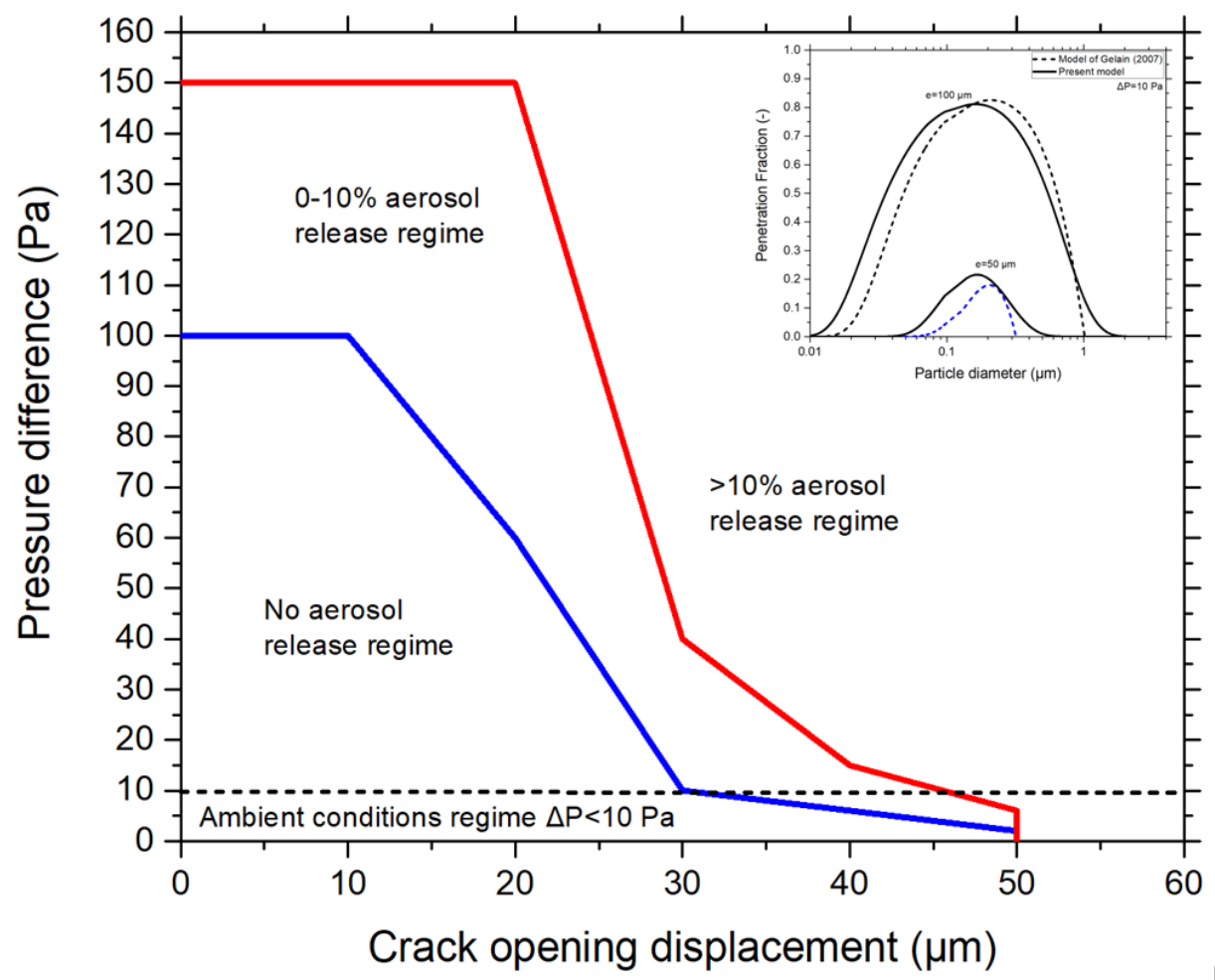

Figure 19. Regimes for aerosol transport through CISCC cracks as a function of pressure difference (penetration as a function of particle size spectrum is shown in upper right figure). "Ambient conditions" refers to conditions following canister depressurization. Highest penetration efficiency is observed for particles in the range 0.1-0.5 $\mu \mathrm{m}$. No particles with diameter $>1 \mu \mathrm{m}$ will be released for cracks with opening displacement ("height") less than $100 \mu \mathrm{m}$. 


\section{CONCLUSION}

A numerical model was developed that enables the calculation of aerosol transport and retention in leak paths and that takes plugging formation into account. The model assumes a one-dimensional flow through a hydraulically equivalent leak path. The description is dynamical (changing duct geometry due to plugging) and mechanistic. The approach is Eulerian, and it relies on the numerical solution of the aerosol transport equation in one dimension using finite differences. An extensive validation exercise was conducted based on comparisons with experimental and theoretical data. The developed model is fairly general since it is based on a generic mechanistic description of the aerosol flow and particle deposition in the leak path, without requiring experimental fittings other than using the leak rate parameters commonly available in practical applications. Despite the approximate agreement of the model with the experimental data, the obtained predictions can be qualified as realistic. This is a major achievement of the model, which has been based on generic aerosol mechanics with no reference or adjustment to experimental data.

Particle penetration through CISCC cracks was estimated using the validated numerical model and by considering the effects of three major deposition mechanisms: diffusion, gravitational settling, and inertial impaction. Particles were assumed to be spherical with a density of $8 \mathrm{~g} / \mathrm{cm}^{3}$ and with diameters ranging from 0.01 to $10 \mu \mathrm{m}$. The particle density was selected to represent particles with similar densities that may be released within a canister, e.g., $\mathrm{Co}-60$ from $\mathrm{CRUD}$ or $\mathrm{UO}_{2}$ particles from fuel pellets. A uniform crack geometry with smooth inner surface and steady airflow through the crack was assumed. Three crack heights (crack opening) were selected, $\mathrm{e}=30 \mu \mathrm{m}, \mathrm{e}=50 \mu \mathrm{m}$, and $\mathrm{e}=100 \mu \mathrm{m}$. Crack width was $10 \mathrm{~mm}$ and crack length $1.27 \mathrm{~cm}(0.5 \mathrm{in}$.). It is noted that in real cracks, irregular geometry and surface roughness might increase particle deposition significantly.

Main conclusions of this study are:

- Diffusion governs the deposition of particles with $\mathrm{d}_{\mathrm{p}}<0.1 \mu \mathrm{m}$. For particles with very low diameter, gravitational and inertial impaction are practically negligible.

- Inertial deposition in the high flow rate regime and gravitational settling in the low flow rate regime govern the deposition for particles having diameter $d_{p}>1 \mu \mathrm{m}$. Diffusion is negligible in that range.

- Particles of several microns in diameter can hardly penetrate through cracks because of the highly efficient removal of such particles by interaction deposition or gravitational settling.

- Particles with $d_{p}<0.01 \mu \mathrm{m}$ or $d_{p}>4 \mu \mathrm{m}$ will not penetrate a crack with height less than $250 \mu \mathrm{m}$.

- For CISCC cracks with height $<100 \mu \mathrm{m}$ particles having diameters in the range 0.1-0.5 $\mu \mathrm{m}$ have the highest penetration across the whole particle spectrum. Larger and smaller particles are readily removed in cracks under the gravitation settling and diffusion, respectively.

- Penetration factor becomes negligible for particles with diameters larger than $1 \mu \mathrm{m}$ even when crack opening is $100 \mu \mathrm{m}$.

- For crack height $50 \mu \mathrm{m}$, particle penetration fraction is less than $30 \%$. At crack height $100 \mu \mathrm{m}$ penetration is less than $90 \%$. This translates in a reduction factor of 3 although crack height decreased by a factor of 2 .

- For crack heights less than $30 \mu \mathrm{m}$, penetration is practically zero. This indicates that penetration varies strongly with crack height and is significantly reduces with smaller crack heights.

- Significant pressure difference is needed, larger than $50 \mathrm{~Pa}$, for considerable penetration to occur from a $30 \mu \mathrm{m}$ crack. Even when $\Delta \mathrm{P}=200 \mathrm{~Pa}$, penetration is less than $60 \%$. For $\Delta \mathrm{P}=50 \mathrm{~Pa}$, penetration is less than $20 \%$ and practically zero for smaller pressure difference. 
- Practically no aerosol release is predicted for cracks with opening displacement ("height") less than $50 \mu \mathrm{m}$ when ambient conditions prevail. Further, no particles with diameter $>1 \mu \mathrm{m}$ will be released for cracks with opening displacement ("height") less than $100 \mu \mathrm{m}$.

- There is experimental evidence that for rectangular geometries, transition to turbulent flow regime starts at $\mathrm{Re}=5-10$. For cylindrical geometries, transition to turbulent flow regime starts at $\mathrm{Re}=400$. This is contrary to widely used $\mathrm{Re}=2300-4000$.

We believe that the modeling calculations presented in this report can provide important insight into the expected values of aerosol release through CISCC cracks and the factors that affect them. Unfortunately, particle penetration through cracks is very sensitive to the minimum crack dimension. The lack of detailed information on the distribution of crack sizes limits our ability to extend the modeling results to real cracks. Nevertheless, information on the overall characteristics can be used to constrain the domain of practical interest. Further progress will require improvements to refine the model in combination with experimental studies. Advances in this area hold the promise of improving the accuracy of consequence assessments by taking the leak path deposition of aerosol into account in the source term. 


\section{REFERENCES}

ANL (Argonne National Laboratory) 2014. Managing Aging Effects on Dry Cask Storage Systems for Extended Long-Term Storage and Transportation of Used Fuel. Report no. ANL-13/15, Revision 2.

Bowen, B.D., Levine, S., Epstein, N. (1976). Fine particle deposition in laminar flow through parallel plate and cylindrical channels. J. Colloids Interface Sci. 54, 375-390.

Clement, C. F. 1995. Aerosol penetration through capillaries and leaks: theory. J. Aerosol Sci. 26, 369-385.

DOE (United States Department of Energy) 2015. Dry Storage Cask Inventory Assessment. Prepared for DOE, Nuclear Fuels Storage and Transportation Planning Project, Jones Jr., Robert H. (Savannah River National Laboratory). Report no. FCRD-NFST-2014-000602, Revision 1, 2015.

DOE 2017a. As-is and Overpack Alternatives. Prepared for DOE, Integrated Waste Management Program. Severynse, T. (SRNL). Report no. SFWD-IWM-2017-000211, Revision 0.

DOE 2017b. Evaluation of Repair, Rework, and Replacement Options for Addressing Nonconforming Dry Storage Systems. Prepared for DOE, Integrated Waste Management Program, Chatzidakis, S. (ORNL). Report no. SFWD-IWM-2017-000210, Revision 0.

DOE 2017c. Assessment of Options for Nonconforming Dry Storage Systems. Prepared for DOE, Integrated Waste Management Program, Chatzidakis, S. (ORNL). Report no. SFWD-IWM-2017-000155, Revision 1.

DOE 2018. Literature Review and Data for Aerosol Transport Model Development. Prepared for DOE, Spent Fuel and Waste Science and Technology Program, Chatzidakis, S. (ORNL). Report no. M5SF18OR010201083, Revision 0.

Drossinos Y. and Housiadas C. (2017). Aerosol Flows. In: Crowe, C. (Ed.), The Multiphase Flow Handbook. CRC Press - Taylor \& Francis (Chapter 20).

Electric Power Research Institute (EPRI) 2017a. Aging Management Guidance to Address Potential Chloride-Induced Stress Corrosion Cracking of Welded Stainless Steel Canisters. Report no. 300200819. Palo Alto, CA: EPRI.

EPRI 2017b. Dry Cask Storage Welded Stainless Steel Canister Breach Consequence Analysis Scoping Study. Report no. 3002008192. Palo Alto, CA: EPRI.

Fuchs, C.N. (1964). The Mechanics of Aerosols. Pergamon Press, Oxford.

Gelain, T. and Vendel, J. (2007). Research works on contamination transfers through cracked concrete walls. Nucl. Eng. Des. 238, 1159-1165.

Lai, A.C.K. et al. (2012). Penetration of fine particles through rough cracks. Atmospheric Environment $60,436-443$.

Lewis, S. (1995). Solid particle penetration into enclosures. Journal of Hazardous Materials 43, 195-216.

Liu, D. And Nazaroff, W. W. (2001). Modeling pollutant penetration across building envelopes. Atmos. Environ. 35, 4451-4462.

Liu, D. and Nazaroff, W.W. (2003). Particle penetration through building cracks. Aerosol Sci. Technol. $37,565-573$.

Mitrakos, D., et al. (2008). A simple mechanistic model for particle penetration and plugging in tubes and cracks. Nuclear Engineering and Design 238, 3370-3378. 
Morton, D.A.V. and Mitchell, J.P. 1994. Aerosol penetration through capillaries and leaks: experimental studies on the influence of pressure. J. Aerosol Sci. 26, 353-367.

Mosley, R. B., et al. (2001). Penetration of ambient fine particles into the indoor environment. Aerosol Sci. Technol. 34, 127-136.

NEI (Nuclear Energy Institute) 2016. Format, Content and Implementation Guidance for Dry Cask Storage Operations-Based Aging Management. Report no. NEI 14-03, Revision 2, December 2016.

Nelson, C. T. and Johnson, R. P. (1975). Aerosol leakage tests, Report ERDA 56.

NRC 2012. Potential Chloride-Induced Stress Corrosion Cracking of Austenitic Stainless Steel and Maintenance of Dry Cask Storage System Canisters. NRC Information Notice 2012-20.

NRC 2016. Standard Review Plan for Spent Fuel Dry Storage Systems at a General License Facility, NUREG-1536, Revision 1.

NRC 2018. Managing Aging Processes in Storage (MAPS) Report. Draft Report for Comment, 2018.

NWTRB 2010. Evaluation of the Technical Basis for Extended Dry Storage and Transportation of Used Nuclear Fuel.

Regtuit, H.E. et al. (1990). The tunnel impactor. A multiple inertial impactor for coarse aerosol. J.

Aerosol Sci. 21 (7), 919-933.

Sandia 2018. Measurement of Particulate Retention in Microchannel Flows. Prepared for DOE, Spent Fuel and Waste Science and Technology Program. Durbin, S. (Sandia). Report no. SAND2018-10522 R, Revision 0.

Shah, R.K., London, A.L. (1978). Laminar Flow Forced Convection in Ducts. Academic Press.

Sutter et al. 1979. Depleted Uranium Dioxide Powder Flow Through Very Small Openings. NUREG/CR1099, PNL-3177, Pacific Northwest Laboratory, Richland, WA.

Tian, M. et al. (2017). Experimental study on the penetration efficiency of fine aerosols in thin capillaries. Journal of Aerosol Science 111, 26-35.

Title 10, Code of Federal Regulations, Part 72 (10 CFR 72), Licensing Requirements for the Independent Storage of Spent Nuclear Fuel, High-Level Radioactive Waste, and Reactor-Related Greater Than Class C Waste.

Wells, A.C., Chamberlain, A.C. (1967). Transport of small particles to vertical surfaces. Brit. J. Appl. Phys. 18, 1793-1799.

Williams, M. M. R. (1994). Particle deposition and plugging in tubes and cracks (with special reference to fission product retention). Progress in Nuclear Energy. 28, 1-60. 